\title{
Sea-ice evaluation of NEMO-Nordic 1.0: a NEMO-LIM3.6-based ocean-sea-ice model setup for the North Sea and Baltic Sea
}

\author{
Per Pemberton ${ }^{1}$, Ulrike Löptien ${ }^{3}$, Robinson Hordoir ${ }^{2}$, Anders Höglund ${ }^{2}$, Semjon Schimanke ${ }^{2}$, Lars Axell ${ }^{2}$, and \\ Jari Haapala ${ }^{4}$ \\ ${ }^{1}$ Swedish Meteorological and Hydrological Institute, 42671 Gothenburg, Sweden \\ ${ }^{2}$ Swedish Meteorological and Hydrological Institute, 60176 Norrköping, Sweden \\ ${ }^{3}$ GEOMAR Helmholtz Centre for Ocean Research Kiel, Düsternbrooker Weg 20, 24105 Kiel, Germany \\ ${ }^{4}$ Finnish Meteorological Institute, 00101 Helsinki, Finland \\ Correspondence to: Per Pemberton (per.pemberton@smhi.se)
}

Received: 13 January 2017 - Discussion started: 20 February 2017

Revised: 5 July 2017 - Accepted: 18 July 2017 - Published: 22 August 2017

\begin{abstract}
The Baltic Sea is a seasonally ice-covered marginal sea in northern Europe with intense wintertime ship traffic and a sensitive ecosystem. Understanding and modeling the evolution of the sea-ice pack is important for climate effect studies and forecasting purposes. Here we present and evaluate the sea-ice component of a new NEMOLIM3.6-based ocean-sea-ice setup for the North Sea and Baltic Sea region (NEMO-Nordic). The setup includes a new depth-based fast-ice parametrization for the Baltic Sea. The evaluation focuses on long-term statistics, from a 45-year long hindcast, although short-term daily performance is also briefly evaluated. We show that NEMO-Nordic is well suited for simulating the mean sea-ice extent, concentration, and thickness as compared to the best available observational data set. The variability of the annual maximum Baltic Sea ice extent is well in line with the observations, but the 19612006 trend is underestimated. Capturing the correct ice thickness distribution is more challenging. Based on the simulated ice thickness distribution we estimate the undeformed and deformed ice thickness and concentration in the Baltic Sea, which compares reasonably well with observations.
\end{abstract}

\section{Introduction}

The Baltic Sea is seasonally ice covered and in the northern part the sea-ice season can last for up to 7 months. The maximum total sea-ice extent is usually reached in late February and between mid-February and mid-March the ice covers on average $45 \%$ of the total Baltic Sea area. However, interannual fluctuations around this mean are very large and during severe winters the entire Baltic Sea can be completely ice covered (Leppäranta and Myrberg, 2009; Vihma and Haapala, 2009).

With $15 \%$ of the world's cargo transportation, the Baltic Sea is one of the heaviest trafficked seas in the world (HELCOM, 2009). Despite the harsh wintertime sea-ice conditions, intense maritime traffic proceeds throughout the year, with ships continuously operating to the northernmost ports of the Baltic Sea. This usually requires some assistance by ice-breakers and traffic restrictions based on the ship's ice class are therefore imposed by the ice-breaking authorities (HELCOM, 2004).

Regular sea-ice forecasts are thus vital to support the intense ship traffic (Löptien and Axell, 2014) and numerical ocean-sea-ice models together with satellite and ship-based observations are used by the operational ice services around the Baltic Sea. Here not only the extent of the ice cover is of interest, but ice thickness and information about the ice types are also highly relevant. Close to the coasts and in shallow areas, the ice usually appears as fast ice while it is drifting elsewhere (Leppäranta and Myrberg, 2009). As a consequence of surface and bottom stresses, due to winds and ocean currents, convergent ice motion can lead to deformations of the ice pack. This creates so-called ice ridges, barriers of very thick ice, which can be up to $30 \mathrm{~m}$ thick (Leppäranta and Myrberg, 2009). In addition, a convergent ice field can lead to high ice pressure that can severely hinder the ice-going traf- 
fic. It is therefore of high importance for the maritime traffic to monitor and forecast the extent of ridged ice and ice pressure (Leppäranta and Hakala, 1992; Löptien et al., 2013).

In addition, results from sea-ice models have also been used for understanding winter maritime traffic and analyzing winter ship navigation accidents (Goerlandt et al., 2016), building a winter navigation risk model (Valdez Banda et al., 2015), and developing data-driven models for ship performance in ice (Montewka et al., 2015).

For the climate system sea ice constitutes a barrier that strongly reduces the exchange of heat, nutrients, and gases as well as impacts the momentum transfer between the ocean and atmosphere. Here numerical ocean-sea-ice models have been used as the main tool to understand how changes in the climate system would impact the state of the Baltic Sea (Haapala et al., 2001; Meier, 2006), how changes in the ice cover affect biogeochemistry (Eilola et al., 2013), and how changes in sea ice impact Baltic ringed seals (Meier et al., 2004).

Clearly the need to model sea-ice processes is an integral part of the ocean-sea-ice forecasting task, crucial for maritime winter traffic studies, as well as an important component of the coupled ocean-ice-atmosphere climate system. Even though the physical processes at work are the same on these different timescales and spatial scales, model limitations have called for different models systems to be used at the Swedish Meteorological and Hydrological Institute (SMHI) in the past for ocean-sea-ice forecasting (Funkquist and Eckhard Kleine, 2007) and climate studies (Meier et al., 2003) of the Baltic Sea. The development of such models is time-consuming and a common model system would thus be beneficial. Here the use of a community model system such as NEMO (Nucleus for European Modelling of the Ocean) (Madec, 2016) provides an excellent tool to keep up with the state-of-the-art model development. This approach has been adopted at the SMHI, where a new NEMO-based configuration - NEMO-Nordic - used both for forecasting and climate purposes, has been set up for the Baltic and North seas.

The aim of this article is to present the sea-ice component of NEMO-Nordic to the community. This is done by evaluating a 45-year long hindcast simulation of the Baltic Sea with a set of observations. The article is outlined as follows: in Sect. 2 we describe the model, simulation, metrics, and observational data set that are used. In Sect. 3 we evaluate the new configuration, focusing on the 45-year long hindcast simulation, followed by a summary and conclusions in Sect. 4. Note that the ocean component of NEMO-Nordic is presented and evaluated in Hordoir et al. (2015) and in a forthcoming separate article (Hordoir et al., 2017).

\section{Methods}

\subsection{Model description}

The NEMO model framework and the integrated Louvainla-Neuve sea-ice model (LIM) provide possibilities to simulate ocean and sea-ice processes on a multitude of timescales and space scales with applications ranging from global climate simulations to regional forecasts. Here we describe our NEMO-Nordic setup that uses the stable NEMO-LIM3 version 3.6 in a regional configuration covering the North and Baltic seas. Below we briefly describe the different components of the configuration with the specific choices of parameter settings and physics options.

\subsubsection{The ocean model}

The main model domain of NEMO-Nordic covers the English Channel, North Sea, and Baltic Sea. In the present study we use a sub-region of the main domain covering only the Baltic Sea and Kattegat to save computational time. This setup has the same physical options and horizontal and vertical resolutions as the larger North Sea/Baltic Sea domain. The only difference is that the open boundary is in Kattegat instead of in the English Channel and the North Sea. The effect of omitting the Skagerrak and North Sea region is very limited for the Baltic Sea ice state as the sea-ice growth and melt is mainly driven by the surface fluxes rather than the advective signal. However, sea ice can occasionally form along the Swedish western coast in the Skagerrak region, and this is obviously not simulated in this setup.

NEMO-Nordic's horizontal resolution is $0.055^{\circ}$ in the zonal direction and $0.033^{\circ}$ in the meridional direction. This amounts to a nominal resolution of $3.7 \mathrm{~km}$ ( 2 nautical miles). Compared to the first baroclinic Rossby radius, which is 2 $11 \mathrm{~km}$ in the Baltic Sea (Alenius et al., 2003; Osinski et al., 2010), this makes the model operate in an eddy-resolving to eddy-permitting regime. The vertical resolution is $3 \mathrm{~m}$ in the upper layers down to $60 \mathrm{~m}$, and then gradually increases to $22 \mathrm{~m}$ at depth, with a total of 56 layers. The vertical discretization uses the $z^{*}$ formulation and the bottom topography is represented by the partial steps approach. The setup utilizes a fully nonlinear free surface formulation with a time splitting of barotropic and baroclinic modes to speed up simulation time. The ocean model time step is $360 \mathrm{~s}$ and the ice model is called every fifth time step. Vertical mixing is represented by the two equation generic length scale formulation (Umlauf and Burchard, 2005). In addition, Laplacian horizontal and isopycnal mixing is used in conjunction with a bottom-boundary layer parametrization (Beckmann and Döscher, 1997).

For further details and evaluation of the NEMO-Nordic ocean model setup, the reader is referred to Hordoir et al. (2015). 


\subsubsection{The sea-ice model}

LIM3 is a dynamic-thermodynamic sea-ice model with a multi-category ice thickness distribution and multi-layer halo-thermodynamics (Vancoppenolle et al., 2009; Rousset et al., 2015). The ice dynamics use a modified elasticviscous-plastic (EVP) rheology (e.g., Bouillon et al., 2009) and account for sea-ice deformation processes (ridging and rafting).

The present NEMO-Nordic builds upon version 3.6 of LIM3. Compared to the polar oceans, sea ice ${ }^{1}$ in the Baltic Sea is only seasonal, generally thinner, and with a much lower brine content due to the low salinities in the Baltic Sea. Thus, some model parameters need to be adjusted to the Baltic Sea conditions. In Table 1 we show the settings of the physical sea-ice parameters that were adjusted in our NEMO-Nordic setup. The settings are also compared to that of a large-scale global ocean configuration (ORCA2-LIM3), a configuration that is included in the NEMO-LIM3.6 model system. Below we briefly describe the rationale behind most of these settings.

In NEMO-Nordic the ice thickness distribution is discretized using five different categories and the thermodynamic calculations use two vertical layers of ice and one layer of snow. When new ice forms in open water it is assumed to have a thickness of $0.01 \mathrm{~m}$. In our setup we neglect all internal halodynamical processes of the sea ice, as initial tests using this option yielded an unstable model, particularly close to river mouths. Instead we use a constant bulk salinity of $0.001 \mathrm{~g} \mathrm{~kg}^{-1}$, which essentially means that the effect of brine pockets is neglected. This value is $10 \%$ of the river salinity used in the model and was chosen for numerical stability reasons. We tested an ice salinity of $0.0 \mathrm{~g} \mathrm{~kg}^{-1}$, but that yielded an unstable model, likewise with an ice salinity higher than the river water salinity. For numerical stability reasons ice models also require some horizontal diffusion. In our configuration, with a relatively high horizontal resolution, we use a relatively low diffusivity constant of $1.0 \mathrm{~m}^{2} \mathrm{~s}^{-1}$. LIM3 has a ridging scheme that accounts for the thickness growth due to sea-ice ridging. In this scheme there is a parameter rn_hstar that adjusts the upper bound of the ridged ice thickness. Since ridges are generally thinner in the Baltic Sea compared to polar oceans, we lowered rn_hstar to $30.0 \mathrm{~m}$ from the default $100.0 \mathrm{~m}$; likewise, we lowered the crossover thickness for a sea-ice ridge instead of raft from $0.75 \mathrm{~m}$ to $0.07 \mathrm{~m}$, with a sharper transition. This value is a Baltic Sea adaption of the analytical modeling work by Parmerter (1975), who suggest $0.17 \mathrm{~m}$ for Arctic conditions. The ice and snow albedos use the default formulation in LIM3 and the snow conductivity the default value of $0.31 \mathrm{~W} \mathrm{~m}^{-1} \mathrm{~K}^{-1}$.

\footnotetext{
${ }^{1}$ In fact, on a micro scale it is brackish ice rather than sea ice. However, the brackish Baltic Sea ice can still be assumed to behave as sea ice (Leppäranta and Myrberg, 2009).
}

In addition, we have implemented a simple fast-ice parametrization since this is not included in the present version of LIM3. Fast ice is an important feature of the Baltic Sea ice cover and usually occurs in coastal and archipelago regions where the ocean depth is shallow. This is done by simply masking out grid points where the depth is below $15 \mathrm{~m}$ in the dynamical components of LIM3 so that the ice remains stationary. The fast-ice mask is deactivated if the total ice volume in a cell is below $0.001 \mathrm{~m}^{3}$, which means that for extremely low concentrations there can be advection of ice in the fast-ice zone. The main effect of the fast-ice parametrization is that a region of more or less undeformed ice is formed close to the coasts, and that the ridges are formed outside of this region.

\subsection{Ice thickness distribution}

On spatial scales of $O(\mathrm{~km})$, the scale of the present sea-ice model, the ice thickness varies considerably due to both thermodynamical growth and mechanical redistribution of ice. To account for such sub-grid-scale ice thickness variations, sea ice is described in terms of an ice thickness distribution $g(h)$, following Thorndike et al. (1975). Here $g(h) \mathrm{d} h$ gives the areal fraction of ice with a thickness between $h$ and $h+\mathrm{d} h$. From the distribution we can calculate the ice concentration $A$ as

$A(x, y, t)=\int_{0}^{\infty} g(h, x, y, t) \mathrm{d} h$

and the mean thickness as

$H(x, y, t)=\int_{0}^{\infty} h g(h, x, y, t) \mathrm{d} h$.

In LIM3 the ice thickness distribution is discretized by defining $n$ ice categories with thickness bounds $H_{i}^{\text {lower }}$ and $H_{i}^{\text {upper }}$ for category $i$. Usually five categories are sufficient to resolve the sub-grid-scale distribution (Bitz et al., 2001). Within each category the ice thickness is free to evolve between $H_{i}^{\text {lower }}$ and $H_{i}^{\text {upper }}$, and as thermodynamical and dynamical processes form or melt the ice, the ice thickness changes and LIM3 accordingly remaps the ice thickness distribution to account for this.

For regional applications, where sea ice usually is thinner than in the polar regions, LIM3 has a new scheme to calculate the ice category bounds (Rousset et al., 2015). Based on an expected domain average ice thickness $\bar{h}$, the category bounds are fit to a function $(1-h)^{\alpha}$ on the interval between 0 and $3 \bar{h}$. In NEMO-Nordic the ice thickness distribution is discretized using five different categories based on a $\bar{h}=0.5 \mathrm{~m}$ giving the lower bounds: $0.0,0.25,0.56,0.95$, and $1.46 \mathrm{~m}$ (also shown in Fig. 10a). 
Table 1. Physical parameters in the sea-ice namelist (namelist_ice_ref) that where changed in NEMO-Nordic compared to the standard global ORCA2-LIM3 that is included in the NEMO-LIM3.6 model system.

\begin{tabular}{|c|c|c|c|c|}
\hline Namelist parameter & NEMO-Nordic & ORCA2-LIM3 & Unit & Description \\
\hline rn_hicemean & 0.5 & 2.0 & $\mathrm{~m}$ & $\begin{array}{l}\text { Expected domain-average ice thickness; value based on obser- } \\
\text { vational studies (Vihma and Haapala, 2009). }\end{array}$ \\
\hline rn_pstar & $2.5 \times 10^{4}$ & $2.0 \times 10^{4}$ & $\mathrm{Nm}^{-2}$ & $\begin{array}{l}\text { Ice strength thickness parameter; value based on previous mod- } \\
\text { eling studies (Leppäranta et al., 1998). }\end{array}$ \\
\hline rn_ahi0_ref & 1.0 & 350.0 & $\mathrm{~m}^{2} \mathrm{~s}^{-1}$ & $\begin{array}{l}\text { Horizontal sea-ice diffusivity, only for numerical reasons, se- } \\
\text { lected as low as possible. }\end{array}$ \\
\hline rn_hnewice & 0.01 & 0.1 & $\mathrm{~m}$ & $\begin{array}{l}\text { Thickness for new ice formation in open water, a low value to } \\
\text { capture thin new ice formation. }\end{array}$ \\
\hline rn_maxfrazb & 0.0 & 1.0 & & $\begin{array}{l}\text { Maximum fraction of frazil ice collecting at the ice base, ne- } \\
\text { glected in this Baltic Sea setup. }\end{array}$ \\
\hline rn_himin & 0.01 & 0.1 & $\mathrm{~m}$ & $\begin{array}{l}\text { Minimum ice thickness used in remapping, a low value to cap- } \\
\text { ture thin new ice formation. }\end{array}$ \\
\hline rn_betas & 1.0 & 0.66 & $\mathrm{~m}$ & Exponent in lead-ice repartition of snow precipitation. \\
\hline rn_icesal & $1.0 \times 10^{-3}$ & 4.0 & $\mathrm{~g} \mathrm{~kg}^{-1}$ & $\begin{array}{l}\text { Bulk sea-ice salinity, chosen for numerical reasons, set to mini- } \\
\text { mum value. }\end{array}$ \\
\hline rn_hstar & 30.0 & 100.0 & $\mathrm{~m}$ & $\begin{array}{l}\text { Determines the maximum thickness of ridged ice; value based } \\
\text { on observations (Vihma and Haapala, 2009). }\end{array}$ \\
\hline rn_hraft & 0.07 & 0.75 & $\mathrm{~m}$ & $\begin{array}{l}\text { Threshold thickness for rafting; value based on analytical mod- } \\
\text { eling (Parmerter, 1975). }\end{array}$ \\
\hline
\end{tabular}

To compare the simulated thicknesses with observations, we use two different metrics:

$\bar{H}=\frac{\sum_{i=1}^{5} g_{i} h_{i}}{\sum_{i=1}^{5} g_{i}}$,

which is the mean ice thickness for each grid cell, the discrete counterpart of Eq. (2) (also called cell-averaged thickness), and

$\bar{H}_{\text {level }}=\frac{\sum_{i=1}^{4} g_{i} h_{i}}{\sum_{i=1}^{4} g_{i}}$

which is a proxy for the undeformed level ice. The upper bound for the fourth category is $1.46 \mathrm{~m}$, which is greater than the maximum thermodynamical ice growth for most conditions of the present Baltic Sea state. In addition, there is a distinct separation in the ice thickness distribution between the first four categories and the last category; see Fig. 10 (this is discussed more in Sect. 3.3). We interpreted this as representing a separation between the thermodynamically and dynamically grown ice, and thus use the first four ice categories as a proxy for level ice and the fifth category as a proxy for ridged ice. We stress that this is just an approximation as rafting and smaller ridges will also be represented by the model in the lower categories. In an effort to assess the precision of this approximation we ran a 5-year test where we turned of all mechanical deformation of ice and then compared it to a control simulation for the same period to get an estimate of thermodynamically grown ice in the fifth class. This resulted in ice volumes (in category five) of 6-20\% in the case with no deformation; however, the ice in the lower ice classes was also strongly impacted due to the missing transfer of ice, and the test was deemed too artificial to assess the precision of the approximation. However, for many applications (e.g., maritime winter traffic) it is the actual thickness rather than the underlying processes that is important.

\subsection{Forcing and simulation}

As atmospheric forcing we use downscaled ERA-40 reanalysis data (Uppala et al., 2006) which, compared to the original ERA-40 reanalysis, features additional regional details which considerably affect the solution of standalone ocean models of the Baltic Sea (Meier et al., 2011). Note that the ERA-40 data set only covers the period up until 2002, and afterwards we use operational analysis from the ECMWF (European Centre for Medium-Range Weather Forecasts) for the downscaling. Using a different data set for the last 4 years could potentially impact our results; however, our analysis shows no evidence of that. The downscaling procedure takes ERA-40 reanalysis data as boundary conditions for the regional Rossby Centre Atmosphere model (hereafter RCA) which features an enhanced (relative to ERA-40) horizontal resolution of $25 \mathrm{~km}$ (Jones et al., 2004; Samuelsson et al., 2010). As shown by (Samuelsson et al., 2010) the approach provides a very realistic climatology. This downscaling approach was successfully used in earlier studies (e.g., Dietze et al., 2014; Hordoir and Meier, 2011; Hordoir et al., 2013; Löptien and Meier, 2011; Löptien et al., 2013). The present forcing is an advancement as it uses the updated atmospheric model RCA4 and spectral nudging (Berg et al., 2013), which 
ensures that the simulated cyclone paths match the actual tracks.

This atmospheric forcing is applied to NEMO-Nordic in a 45-year long (1961-2006) hindcast simulation. The simulation is initialized from rest with climatological salinity and temperature distributions. The simulation starts in January 1961 with no ice present in the model. As the seasonal sea ice disappears every summer the spinup of the ice cover is usually short and already at the next winter the ice cover is well adapted. To account for the ice spinup we start our analysis in the beginning of the 1961/1962 ice season. On the open boundary in Kattegat the model is forced by sealevel variations from daily tide gauge data. For temperature and salinity on the open boundary and runoff draining into the Baltic Sea, we use monthly climatological values. Meier et al. (2012) showed that for temperature such an approach is sufficient for the Baltic Sea as most of the trend comes from the atmospheric forcing. However, in Kattegat close to the open boundary in the sub-region, the solution can of course be affected by the simplified boundary conditions.

\subsection{Observational data}

We use several observational data sets to evaluate the sea-ice model. An extensive historical data set, named BASIS, covers the winters 1960/1961 to 1978/1979. This data set contains the, at that time, best available information on the ice concentration, thickness, as well as dominant ice types. BASIS is based on hand-drawn sea-ice charts which were provided by the local weather services for shipping. The sea-ice charts were derived from direct ice measurements and estimates from voluntarily observing ships, coast guards, ice breakers, lighthouses, and harbor authorities. Additional information came from over-flights by the FMI, the SMHI, and the Swedish Air Force. From the late 1960s onwards satellite observations were partly included. Thus, the underlying ice charts were extrapolated from the irregular (as regards space and time) observations. The associated uncertainties are unclear and are presumably largest away from the major shipping lines. Nevertheless, BASIS is the best available information on historic ice conditions in the Baltic Sea. These ice charts were collected and then digitized in 1981 in a joint project of the Finnish Institute of Marine Research (today the FMI) and the SMHI. The original data were hard to access as BASIS ice was designed for storage on punchcards. Thus, Löptien and Dietze (2014) provided an easier-to-access version in the NetCDF free file format via www.baltic-ocean.org (or PANGEA https://doi.org/10.1594/PANGAEA.832353). BASIS ice thicknesses were originally indexed by numbers from 1 to 9. These numbers were assigned to thickness classes (1-2, 3-6, 7-12, 13-20, 21-30, 31-42, 43-56, 5772 , and more than $73 \mathrm{~cm}$ ). Thus a lower bound for the uncertainty when it comes to ice thickness is the precision given by these classes. Note that when we calculate integrated metrics, e.g., total ice extent and total ice volume, the BASIS data set is first interpolated to the same grid as NEMO-Nordic and then masked using the land-ocean mask of the ocean model. This is done to mask out Skagerrak and to have comparable total areas for the Baltic Sea.

In addition to BASIS, we use modern ice charts, called IceMaps, (which interpolate similar observations to those in BASIS); the Swedish Ice Service of the SMHI also provided weekly ice thickness measurements (1971-2010) in the fastice zone at stations Järnäs $\left(19.41^{\circ} \mathrm{E} 63.26^{\circ} \mathrm{N}\right)$ and Kemi $\left(24.31^{\circ} \mathrm{E} 65.4^{\circ} \mathrm{N}\right)$. These are located in the Bothnian Bay and Bothnian Sea, respectively. Additionally, we use airborne EM ice thickness measurements in the basin interiors of the Gulf of Finland and Bothnian Bay, which were collected on 23 February 2003, 14 March 2004, and 13 March 2005, all within the IRIS project (Haas, 2004). It is, however, important to keep in mind that comparing point measurements to the model accounts for very different scales and has to be considered with some caution.

To evaluate the sea surface temperature (SST) we use conductivity, temperature, and depth (CTD) sensor casts from SMHI and a satellite-derived data set from the Bundesamt für Seeschifffahrt und Hydrographie (BSH) (Loewe, 1996). The CTD casts where done on a close to monthly basis at stations Anholt E, Fladen, BY15, BY31, MS4, NB1, and F9; for the location, see Fig. 1 and, for the time period, Fig. 5. The BSH data consist of a high-quality satellite SST data product compiled into a monthly data set covering the period 19902006. Also, here it is important to be cautious when interpreting model biases as the modeled SST represent the temperature of the upper $3 \mathrm{~m}$, whereas the CTD cast and BSH represent the near-surface and surface values, respectively. For the snow thickness evaluation we use data of annual maximum thickness from two different stations, Kemi and Hailuoto (see Fig. 1), covering the periods 1961-2005 and 1974-2006, respectively. These data were provided by FMI. For the air temperature evaluation we use data from SMHI's meteorological archive. Here a set of observations from caisson lighthouses, lightships, and small islands in the Baltic Sea were used; see the map and legend in Fig. 1 for the locations and sampling periods.

\section{Model evaluation}

In this section we evaluate NEMO-Nordic's performance against a set of different observational data sets. The main focus is on the long-term statistics of important sea-ice parameters such as sea-ice concentration, extent, and thickness. For the climate system any changes in these sea-ice parameters are crucial and are thus important to evaluate for future climate studies and related studies on, e.g., winter navigation and hazard. We also briefly compare single days when the ice cover reached its maximum extent, for two extreme winters. This is done to evaluate the model's capability to capture extremes on daily timescales, which is important for fore- 


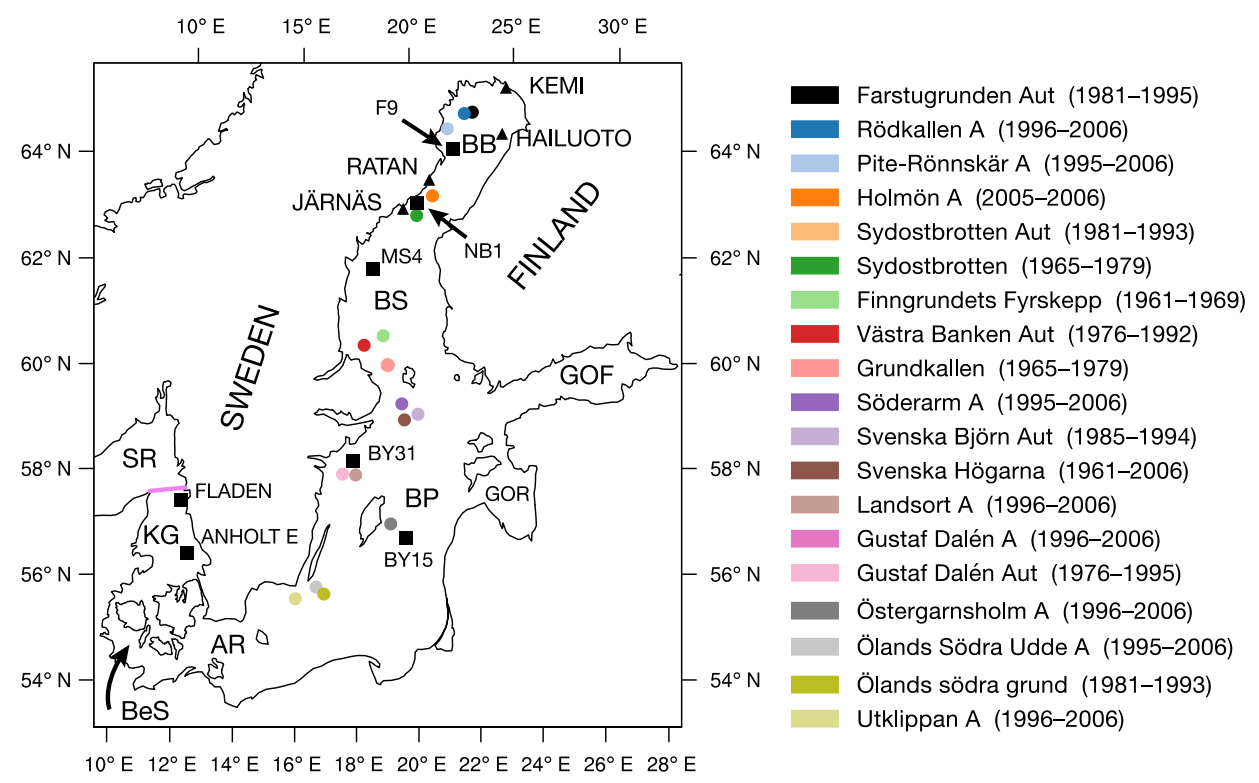

Figure 1. Map showing names of places mentioned in the text; the sub-basins are abbreviated. BB: Bothnian Bay; BS: Bothnian Sea; GOF: Gulf of Finland; GOR: Gulf of Riga; BP: Baltic proper; GR: Gulf of Riga; KG: Kattegat; AR: Arkona Sea; BeS: Belt Sea; and SR: Skagerrak. The pink line shows the open boundary in Kattegat; the black triangles show the coastal sites Hailuoto, Kemi, Ratan, and Järnäs; and the black squares show the Fladen, Anholt E, BY15, BY31, MS4, NB1, and F9 stations. The air temperature stations are depicted by the dots color coded according to the legend to the right; the time period for each air temperature station is shown within the parentheses.

casting purposes. However, we stress that the model data are from a hindcast simulation, which is a totally different mode of operation compared to how sea-ice forecasts are run. Before evaluating the sea-ice parameters we evaluate the simulated SST, $2 \mathrm{~m}$ air temperature, and snow forcing.

\subsection{Evaluation of $2 \mathrm{~m}$ air temperature, snow thickness, and sea surface temperature}

In this section we aim at evaluating the biases of some of the forcing parameters that impact the ice cover: the $2 \mathrm{~m}$ air temperature, snow thickness, and sea surface temperature. The parameters are chosen based on the available observations that we could gather in the seasonally ice-covered model domain. We stress that to robustly assess the thermal exchanges occurring between the ice-ocean-atmosphere interfaces, we lack observations of important components of the full radiative and turbulent heat fluxes, and the analysis is thus somewhat incomplete. A more rigorous evaluation of the atmospheric biases is desirable and urgent, but is beyond the scope of this article. In addition, the approach we use by forcing NEMO-Nordic with a passively coupled downscaling of ERA-40 also has its shortcomings, e.g., damping of heat anomalies and biases related to the prescribed lower boundary conditions of the atmospheric model. Some of these issues are investigated and discussed by Gröger et al. (2015).

We now compare observed $2 \mathrm{~m}$ air temperatures at a selected number of locations in the northern Baltic Sea with the downscaled ERA-40 atmospheric forcing data. Figure 2 shows the long-term wintertime $2 \mathrm{~m}$ air temperature biases at the different stations for two periods, before and after 1979. Note that the samplings at the stations cover different time periods (see the legend in Fig. 1), and are thus not strictly comparable. The time period division of before and after 1979 is intended to reflect systematic biases for the BASIS period (the first part) and for the latter decades (the period when we have satellite observations of SST). For the first period most stations show an overestimation (downscaled ERA-40 forcing being warmer than the observations) during January-March, with Sydostbrotten in the Bothnian Bay, Grundkallen in the southern Bothnian Sea, and Svenska Högarna in the northern Baltic proper standing out most, with maximum biases around $0.5-2.0^{\circ} \mathrm{C}$. In April, on the other hand, some stations show a negative bias, while others show a positive bias with a range of $-0.8-0.9^{\circ} \mathrm{C}$. Here Finngrundets Fyrskepp, Grundkallen, and Svenska Högarna suggest a positive bias in the southern Bothnian Sea/northern Baltic proper. The Sydostbrotten station yields a negative bias in the Bothnian Bay for April, and the same for the Västra Banken Aut and Gustaf Dalén Aut; however, the latter two only cover 3 years for this time period and might thus not be representative. For the second period some stations (these are only located in the Bothnian Bay) show a large positive $\left(1.1-2.2^{\circ} \mathrm{C}\right)$ bias for January-March, while other stations show a more mixed signal with either a smaller negative or positive bias in the range $-0.5-0.7^{\circ} \mathrm{C}$. It is hard to distinguish a strong coherent geographical signal for the January-March period as nearby stations covering the same period can give inco- 

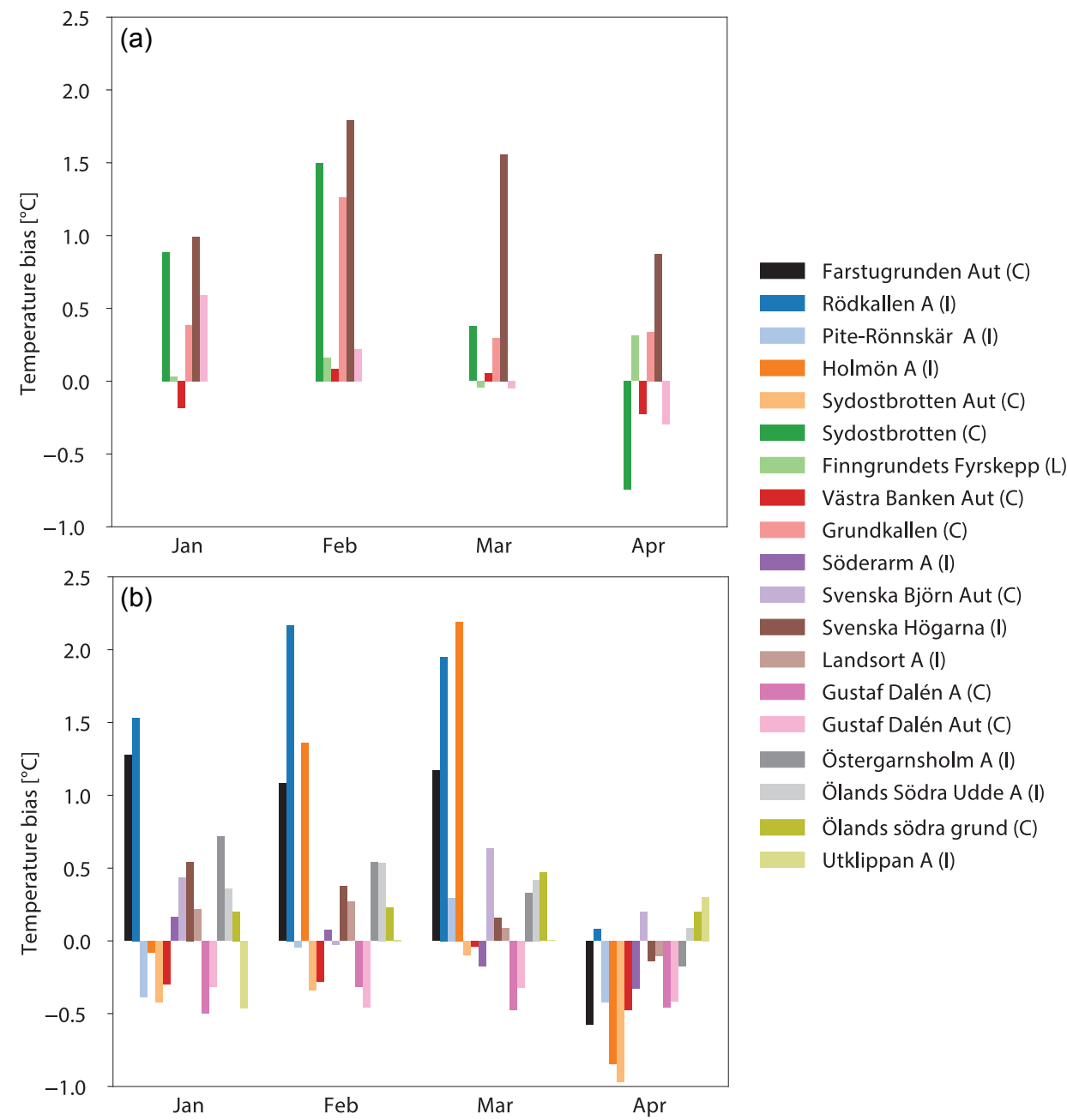

Figure 2. Long-term monthly mean January-April $2 \mathrm{~m}$ air temperature bias $\left({ }^{\circ} \mathrm{C}\right.$ ). The bias is calculated for before 1979 (a) and after 1979 (b); the stations are arranged in an approximately north-to-south order going from the leftmost to the rightmost bar in each month. A positive bias means that the model air temperature forcing is warmer than the observations. After each name the type of measurement platform is given. C: Cassion Lighthouse; L: Lightship; I: Island.

herent biases, e.g., the January bias at Rödkallen and PiteRönnskär showing both positive and negative offsets, respectively. In April on the other hand, the signal is more coherent, with many stations both in the Bothnian Bay, Bothnian Sea, and northern Baltic proper showing negative biases of -1.0 to $-0.5^{\circ} \mathrm{C}$. We caution that the observations are made on different measurement platforms which might have a local climate depending on the location. For instance, observations made on small islands (see the legend in Fig. 2 for the measurement platform type) might be impacted by land, which due to the resolution is not present in the downscaling, and might therefore show larger seasonal cycles and are thus not representative of the temperature over the ocean. Here, e.g., Pite-Rönnskär and Holmön stand out compared to other stations. On the smaller platforms (caisson lighthouses and lightships), on the other hand, the representability of the over-ocean temperature can be assumed to be better.

We now continue to evaluate NEMO-Nordic's snow thickness. Due to its relatively low thermal conductivity the snowpack has an isolating effect on the underlying sea ice, and any biases in the simulated snow thickness will impact the ice growth and melt. Figure 3 shows a comparison of the simulated and observed maximum annual snow thicknesses from two stations in the Bothnian Bay. For these two stations it is clearly seen that the model has a problem simulating the observed snow cover. For Hailuoto years with a thinner snow cover $(10-25 \mathrm{~cm})$, the simulated snow cover has a smaller offset, less than $3 \mathrm{~cm}$, while for years with a thicker snow cover there is a much larger offset, with the model underestimating the snow cover by $8-37 \mathrm{~cm}$. At Kemi there is an overestimation by up to $11 \mathrm{~cm}$ for the years with a thin- 


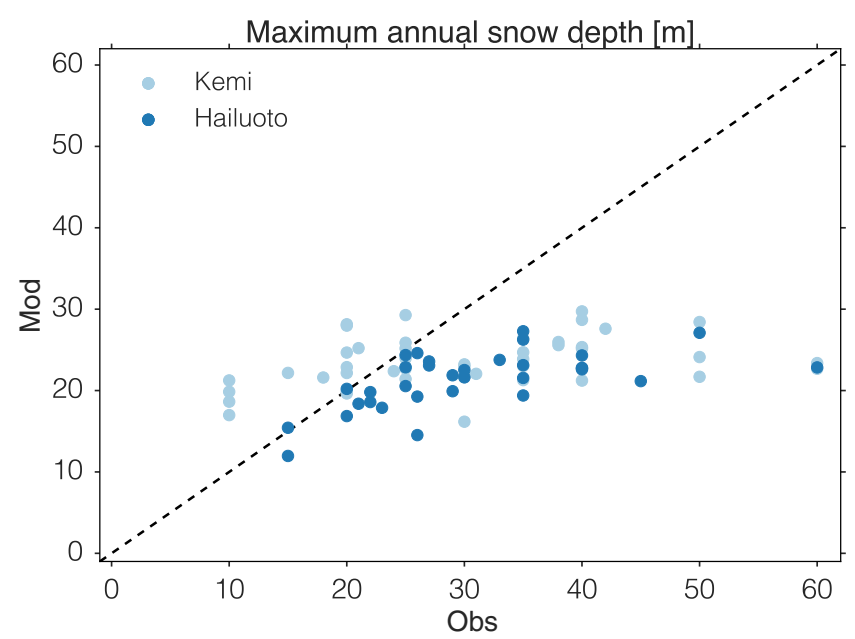

Figure 3. Comparison between observed and simulated maximum annual snow depths at two stations (Kemi and Hailuto; see Fig. 1) in the Bothnian Bay. Observed snow depths are on the $x$-axis and NEMO-Nordic snow depths on the $y$-axis. The Hailuoto station covers the period 1974-2006 and the Kemi station the period 19612005.

ner snow cover, while for years with a thicker snow cover the model has, similar to Hailuoto, a strong underestimation of $7-37 \mathrm{~cm}$. The temporal correlation at Kemi is quite low (0.35), while at Hailuoto it is somewhat higher (0.60). By inspecting the long-term change in snow thickness bias (not shown), we found that the offset is large in the beginning of the simulation and decreases towards the end of the simulation at both stations. We caution that comparing the snow thickness at only two stations is problematic due to the large spatial and temporal variability of the snow cover. However, our results with an underestimation of the snow cover around the Bothnian Bay and Bothnian Sea are also in line with what Samuelsson et al. (2010) found for a number of stations along the Swedish coast in this region, in their evaluation of the RCA model.

The SSTs reflect the air-sea interaction of heat and biases in the SSTs indicate that either the atmospheric forcing and/or the ocean dynamics could be misrepresented. Any such biases will also affect the growth of sea ice and we therefore briefly evaluate the SST biases in NEMO-Nordic in the following. Here we compare the simulated SST with a satellite-derived SST product from BSH and with CTD casts at a few stations in the Baltic Sea and Kattegat. Figure 4 shows the long-term (1990-2006) wintertime SST biases over the model domain. We caution that in regions which usually are ice-covered these means are heavily weighted to ice-free conditions as the satellite sensor has limited capabilities to estimate under-ice SSTs. We have therefore masked out these areas using an observed ice concentration greater than $50 \%$ as an indication of suspicious points. As seen in Fig. 4 NEMO-Nordic tends to be colder than the BSH data

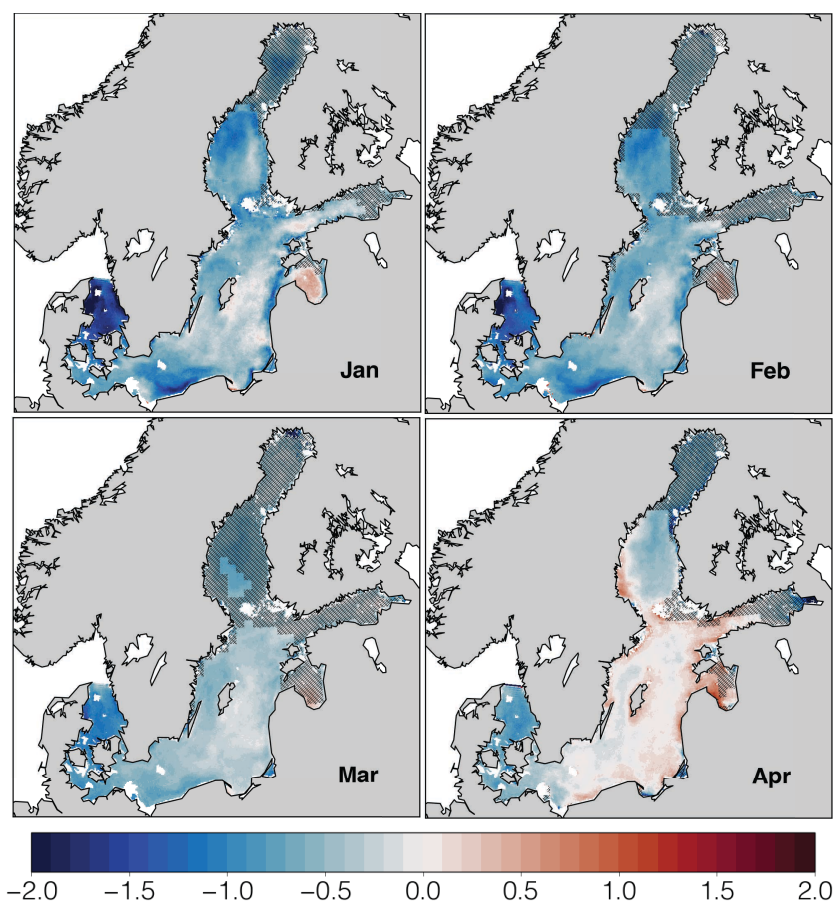

Figure 4. Long-term monthly mean January-April SST bias $\left({ }^{\circ} \mathrm{C}\right)$ for the period 1990/1991-2005/2006. Positive values mean that NEMO-Nordic is warmer than the BSH satellite observations. Areas where the BASIS/IceMap ice concentration is greater than $50 \%$ have been hatched.

set over most of the model domain, for the January-March period. An exception is in the Gulf of Riga, where there is a persistent positive bias of $\sim 0.5^{\circ} \mathrm{C}$. Some parts of the central Baltic proper and Gulf of Finland also exhibit a small positive bias (less than $0.1^{\circ} \mathrm{C}$ ). In April, on the other hand, NEMONordic has a pronounced positive bias (of up to $0.8^{\circ} \mathrm{C}$ ) in the coastal regions of the Baltic proper, Bothnian Sea, and the outer Gulf of Finland. In the central parts of the Baltic proper the bias is very small (less than \pm 0.2 ). Calculating the area mean bias over the Baltic proper yields a change from a negative -0.5 bias for January-March to a small positive bias (less than $0.1{ }^{\circ} \mathrm{C}$ ) for April. The Bothnian Sea and Gulf of Finland, on the other hand, all have negative area mean biases for all winter months. Another evident feature is that there is a persistent strong negative bias in Kattegat, particularly pronounced in January and February. The January-April mean bias for the entire Kattegat region is $-1.2^{\circ} \mathrm{C}$.

The BSH data only cover the last 2 decades of the simulation and to further evaluate the simulated SSTs we now compare NEMO-Nordic with CTD data from seven different stations which have long-term monitoring, three in the Bothnian Bay and Bothnian Sea (F9, NB1, MS4), two in the Baltic Sea (BY15 and BY31) and two in Kattegat (Fladen and Anholt E). All available data in the upper $3 \mathrm{~m}$ are averaged for each date. Note that the depth sampling can change from station to station. Similarly to the air temperature bias 


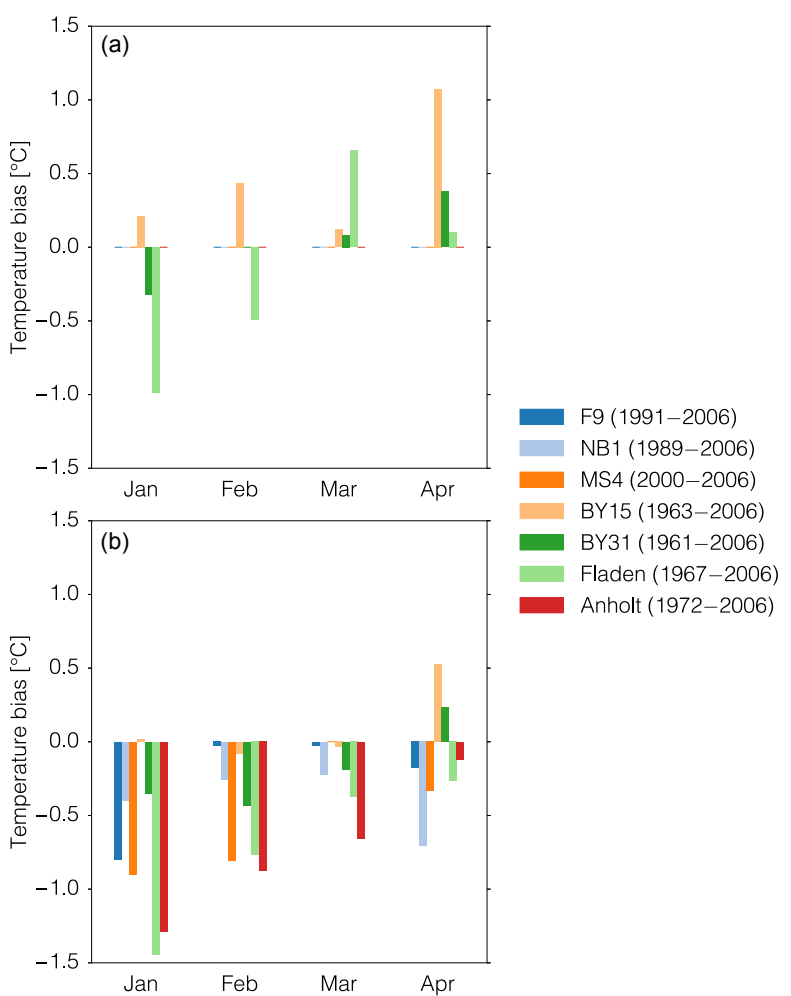

Figure 5. January-April SST biases for a selected number of stations (arranged in north-south order) estimated from CTD casts. The upper panel shows biases for stations available before 1979, and the lower panel after 1979. The full time period of each station is given in the figure legend; for the locations of the different stations, see Fig. 1. Positive values mean that NEMO-Nordic is warmer than the CTD casts.

analysis, we have divided the data into two periods, before and after 1979; see Figure 5. For the first period only data in the Baltic Sea and Kattegat are available. As seen, the station representing the central Baltic proper (BY15) has a positive bias with a maximum offset in April of $1.1^{\circ} \mathrm{C}$. The station representing the western Baltic proper (BY31) has a negative bias in January and a positive bias in March and April. In Kattegat the Fladen station shows a large negative bias $\left(-1.0^{\circ} \mathrm{C}\right)$ in January that is reduced in February and shifted towards a positive bias in March and April. For the second period there are also data from the Bothnian Bay and Bothnian Sea. This period also covers the satellite data period. Here almost all stations (except BY15) have negative biases for the January-March period, with the largest biases seen in January, in Kattegat $\sim-1.4^{\circ} \mathrm{C}$. In April, the Bothnian Bay, Bothnian Sea, and Kattegat stations have negative biases, while the Baltic proper stations have positive biases. Clearly the systematic biases seen in the stations agree quite well on the sign and magnitude of the offset compared to the satellite-derived data.

To end this section, we summarize all the biases seen in the $2 \mathrm{~m}$ air temperature, snow thickness, and SSTs. For snow thickness we see a strong underestimation, especially for years with a thicker snow cover, and the variability at the investigated stations is quite poor both in timing and amplitude. From the SST biases we see an overly cold Kattegat region, particularly in January and February. This seems to persist throughout most of the simulation. These results are in line with the study by Gröger et al. (2015), who found that the dynamical downscaling of ERA-40 has a cold air temperature bias, due to a cold bias in the prescribed SST. This region is also close to the open boundary, and the relatively simple boundary conditions could also impact the SSTs in this region. For the Baltic Sea the signal is different. During the latter period we see a cold bias for most of the Baltic Sea (January-March). In April, on the other hand, the northern parts are still too cold, while the central parts are too warm. The overly warm SSTs in April are also present for the first period. The $2 \mathrm{~m}$ air temperature biases give a much more incoherent picture, with biases in opposite directions at nearby stations. We note that in Samuelsson et al. (2010) they found that land areas in northern Scandinavia experience a positive $2 \mathrm{~m}$ air temperature, while southern Sweden showed a negative bias. Comparing the $2 \mathrm{~m}$ air temperature biases to the SST biases is challenging: at some nearby stations (e.g., Gustaf Dalén Aut and BY31), the sign of the offset is in the same direction, while at others it is in the opposite direction (e.g., Landsort A and BY31). As we have no information on the biases in the shortwave, longwave, and latent heat fluxes, it is hard to attribute the causes of the two main signals: the basin-wide cold SSTs, and the warm central Baltic proper in April. We can speculate that it is related to the prescribed lower boundary conditions (SSTs and ice cover) which impact the cloud cover and radiative fluxes in the downscaling (e.g., Gröger et al., 2015; Hunke and Holland, 2007). This in turn impacts the onset and retreat of the ice cover. It is, however, beyond the scope of the present study to further explore the underlying reasons behind the SST biases.

\subsection{Sea-ice concentration and extent}

The extent of the sea-ice cover and its concentration are two important parameters that a sea-ice model needs to simulate well from both climatological and forecasting perspectives. Here we show the long-term spatial coverages and the time variability of the total sea-ice extent in the Baltic Sea.

Figures 6 and 7 show the long-term (1961-1979) monthly mean sea-ice concentrations for both NEMO-Nordic and the BASIS data set. As seen, the general agreement is quite good for this period. In January both the model and BASIS agree on the coverage in the Bothnian Bay, Bothnian Sea, Gulf of Finland, and Gulf of Riga. However, the ice coverage in Kattegat is much overestimated in NEMO-Nordic. In February when the Baltic Sea ice coverage usually reaches its maximum, NEMO-Nordic and BASIS agree very well, showing that the Bothnian Bay and Sea, Gulf of Finland, and Gulf of Riga are completely ice-covered. The Belt Sea and Katte- 


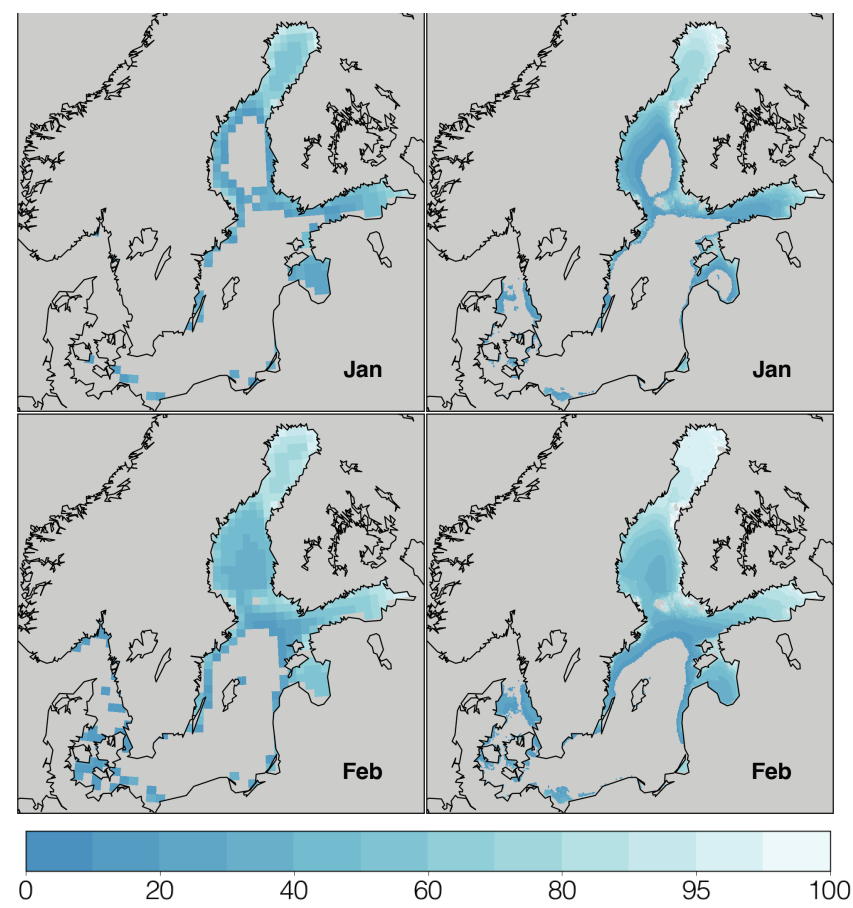

Figure 6. Climatological mean ice concentration for January and February, for the period 1961/1962-1978/1979. The left column shows the sea-ice concentration for BASIS and the right column that for NEMO-Nordic. Note that grid cells with an ice concentration lower than $15 \%$ have been masked out and that grey sea areas denote missing or masked values.

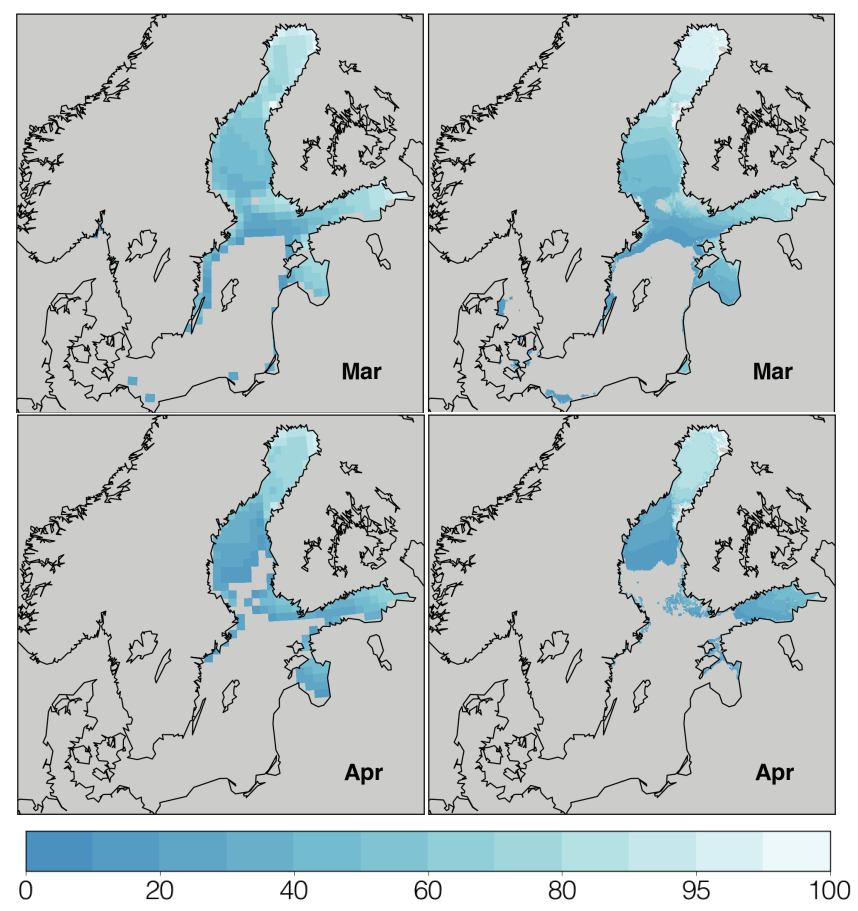

Figure 7. Same as Fig. 6 but for March and April.

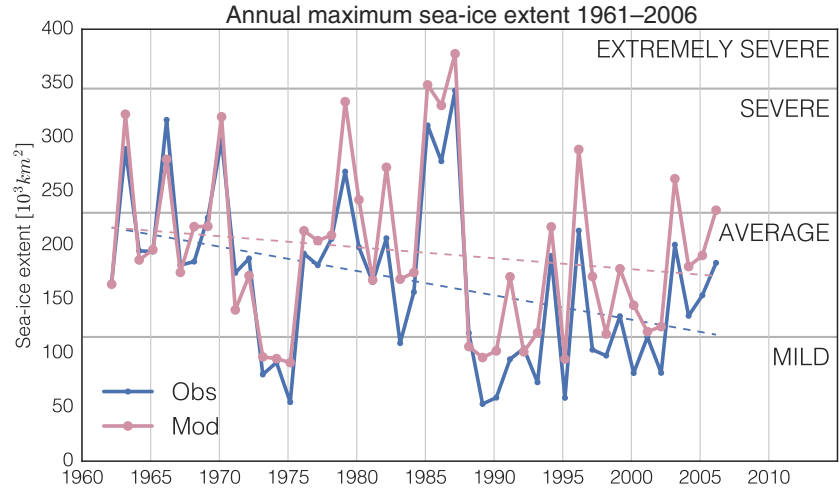

Figure 8. Simulated (red solid line) and observed (blue solid line) annual maximum daily sea-ice extents in the Baltic Sea, for the period 1961/1962-2005/2006. The horizontal grey lines show the limits for winters with a maximum sea-ice extent in the Baltic Sea classified as mild, average, severe, and extremely severe, respectively. The dashed red and blue lines show the linear trends for simulated and observed maximum sea-ice extents, respectively.

gat are also completely ice-covered but with much lower ice concentrations, while only the coastal regions in the Baltic proper and Arkona Sea on average are ice-covered. In March the agreement is also good, although NEMO-Nordic simulates some sea ice in Kattegat. In April the reduction of sea ice is evidently stronger in the model, which shows much less ice in the Bothnian Sea and Gulf of Riga. We note that the overly large ice cover in Kattegat, in January (and February), and the overly low ice cover in the central parts of the Baltic proper are consistent with the evaluated SST biases at Fladen and BY15, respectively.

The annual maximum Baltic Sea ice extent (MBI) is a widely used metric to describe climate variability in the region, and the first recordings date back to 1720 (e.g., Vihma and Haapala, 2009, and reference therein). To evaluate the MBI we compare NEMO-Nordic with observational estimates from BASIS extended with IceMaps from the Swedish Ice Service. Note that in this study sea-ice extent is calculated as the area where sea-ice concentration is at least $15 \%$, and that we have excluded sea ice in the Skagerrak region from the observational estimates as this region is missing in the present configuration. Figure 8 shows the interannual variability of the MBI. The long-term (1961-2006) simulated and observed means (standard deviations) are 194 (78) and $167(77) \times 10^{3} \mathrm{~km}^{2}$, respectively, and the correlation between the model and observations is 0.93 . The simulated trend $\left(-10 \times 10^{3} \mathrm{~km}^{2} \mathrm{decade}^{-1}\right)$ for the $1961-2006$ period is much lower than the observed trend $\left(-23 \times 10^{3} \mathrm{~km}^{2} \mathrm{decade}^{-1}\right)$. For a level of $p \leq 0.05$ the null hypothesis of no trend could not be rejected for the simulated trend $(p=0.26)$, while the observed trend ( $p=0.009$ ) falls well below this level. Clearly there is a shift, with a change in the systematic offset occurring somewhere around the period 1973-1976, where the model goes from a period (1961-1976) with a smaller neg- 


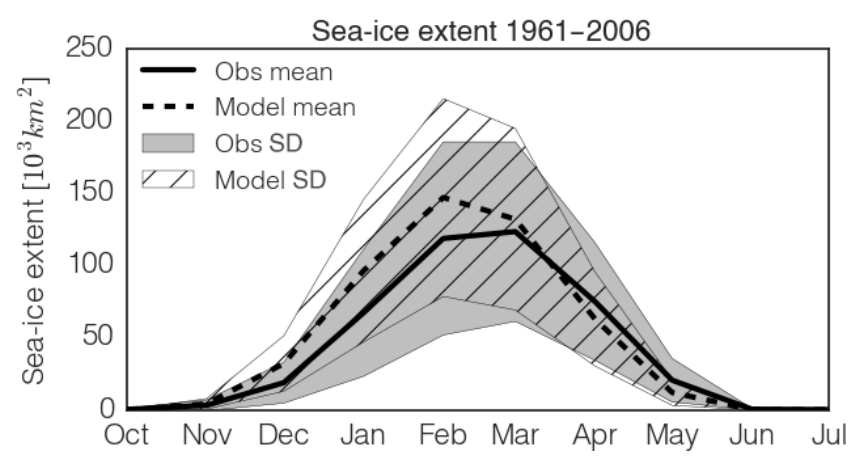

Figure 9. Seasonal cycles of simulated and observed total sea-ice extents in the Baltic Sea. The lines show the seasonal monthly means and the filled envelopes show the \pm 1 standard deviations. The seasonal cycles are calculated for the periods 1961/19622005/2006. Note that Skagerrak has been masked out in the observational data set.

ative bias towards a period (1977-2006) with a larger positive bias. Calculating the decadal biases yields offsets of -1 , $-3,15,20$, and $28 \%$ for the 5 decades. After the bias shifts to becoming positive, the trends also agree better with -32 and $-27 \times 10^{3} \mathrm{~km}^{2}$ decade $^{-1}$ for NEMO-Nordic and observations, respectively. The SST biases at BY15 and Fladen also reflect this shift, with a transition towards a more negative bias or a lower positive bias for the latter decades.

In the Baltic Sea ice winters are usually classified, following Seinä and Paluso (1996), as mild, average, severe, and extremely severe based on the MBI. For the period 19612006 NEMO-NORDIC (observational estimates) shows 8 (15) mild, 25 (23) average, 10 (7) severe, and 2 (0) extremely severe winters. Note that since we have excluded Skagerrak from our integration, the classification statistics are not directly comparable to other studies, and the observations tend to show statistics weighted towards the milder end of the scale due to the regridding and masking of the data. The classification statistics and Fig. 8 show that the model underestimates the total ice extent and number of mild winters, especially during the latter decades. By inspecting year-by-year MBI distribution (see the animation in the supplemental material), we identify particularly two problem areas, Kattegat and the Bothnian Sea, where the model tends to overestimate the MBI ice cover. This occurs for severe, average, and mild winters, but impacts the observation-model intercomparison most for mild winters, which are more dominant during the last 2 decades.

Figure 9 shows the long-term mean monthly seasonal cycles and standard deviations. It is seen that there is a faster increase in ice cover growth and a slightly earlier retreat of the ice cover on average in NEMO-Nordic. The simulated monthly annual maximum of $147 \times 10^{3} \mathrm{~km}^{2}$ is $18 \%$ higher than the observed ice cover and occurs in February rather than March, based on monthly averages. The maximum monthly simulated standard deviation of $69 \times 10^{3} \mathrm{~km}^{2}$ is $3 \%$ higher than the observed standard deviation, occurring in the same month (February). By separating the first 2 decades, and from the last 3 decades (not shown), we see that the seasonal cycle in NEMO-Nordic is well in line with the observational estimates for the first 2 decades, with a better match of the seasonal cycle and an error of less than $9 \%$ in the monthly based annual maximum, while for the latter period the seasonal cycle is overestimated by $29 \%$.

Based on daily data we now discuss the day of MBI. For the full period (1961-2006) we see that on average the MBI occurs on the 53rd and 56th days of the year for NEMONordic and the BASIS/IceMap data set, respectively, i.e., at the end of February. In some years it can occur early in January, both in the model and observations, while for most years it tends to occur in the period mid-February to midMarch. Inspecting the absolute difference in the day when the MBI occurs reveals an average offset of 9 days between the model and the observations. Some years the difference is quite extreme, with up to 50 days of offset, while most years it occurs within a week of the observed maximum. As the BASIS/IceMap data mostly are produced on a one to two times per week basis, a better precision than within a week can not be expected. For years when the difference is large, the winter conditions usually experience two or more cold spells which could be separated by up to a month, and the simulated maximum then occurs during a different cold spell compared to the observed maximum.

Our analysis shows that, overall, NEMO-Nordic agrees reasonably well with the BASIS data sets in terms of seaice concentration and extent, and variability of the MBI. We identified problem areas in Kattegat and the central Baltic Sea/Bothnian Sea which lead to an overly high sea-ice extent during the MBI. This leads to an overestimation of the total sea-ice extent, particularly in the last 3 decades. From the long-term seasonal cycle of total sea-ice extent we see faster growth and an overly early ice retreat in spring. Most of these offsets in the ice cover are in accordance with the already discussed SST biases; however, we lack information on the observed heat fluxes at the ice-ocean-atmosphere interfaces, preventing us from attributing the driving causes of these anomalies.

\subsection{Sea-ice thickness, volume, and deformation}

Sea-ice thickness is another important sea-ice parameter that both reflects the thermodynamical and dynamical evolution of the ice pack. Here we evaluate the sea-ice thickness distribution as well as the long-term mean sea-ice thickness, seaice volume, and ice concentration in the thickest category, where the latter is used as a proxy for the sea-ice ridge concentration.

The sea-ice thickness distribution yields information on both the thermodynamical and dynamical ice growth. The dynamical ice growth tends to affect the extreme ends of the distribution when ridging and rafting create thicker ice 


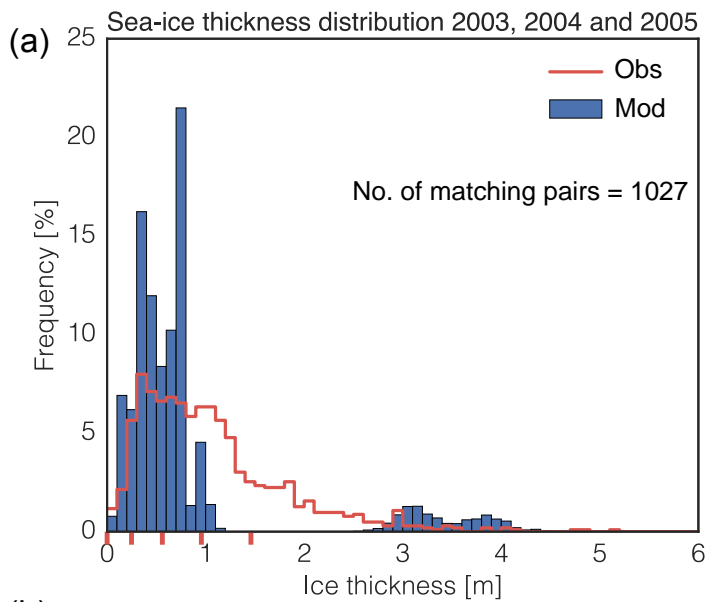

(b) $\quad 18^{\circ} \mathrm{E} \quad 20^{\circ} \mathrm{E} \quad 22^{\circ} \mathrm{E} \quad 24^{\circ} \mathrm{E} \quad 26^{\circ} \mathrm{E} \quad 28^{\circ} \mathrm{E} \quad 30^{\circ} \mathrm{E}$

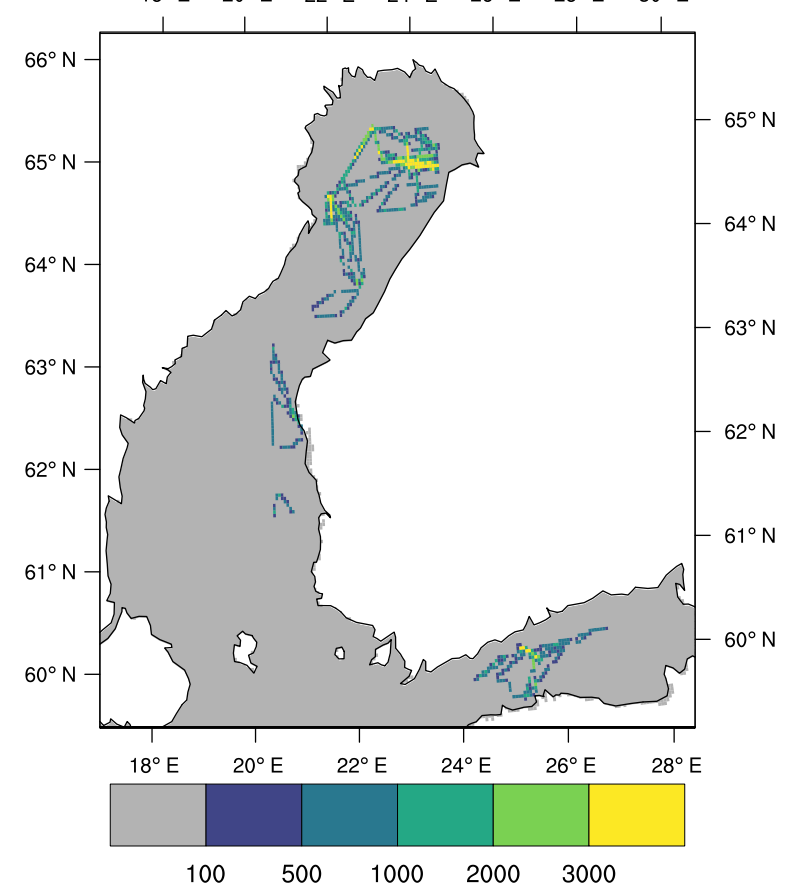

Figure 10. (a) Sea-ice thickness distributions calculated from the gridded EM data (red) and the simulation (blue). (b) shows the number of sub-grid observations of the gridded EM data. The red tick lines in (a) show the limits for the five ice categories. Note that the upper limit of the last ice category - which is unbounded - is not shown.

and open water, while thermodynamical processes tend to populate the distributions towards a center value (Weeks, 2010). Figure 10 shows the simulated and observationally estimated sea-ice thickness distributions, calculated as an average of the 3 days during 2003-2005 winters when the EM ice thickness measurements were carried out. The EM bird system measures the total thickness of sea ice and snow thickness, and we thus include both these quantities in the NEMO-Nordic distribution. As seen in Fig. 10b the EM data sampling is quite sparse and mostly reflects the conditions in the central Bothnian Bay and Gulf of Finland, regions where we expect to find a wide range of thicknesses, including ridges. The mean thicknesses of NEMO-Nordic and the observational estimates are 84 and $113 \mathrm{~cm}$, respectively. Our snow thickness analysis indicated that the model has an overly thin snow cover. This could perhaps be a contributing factor to the lower mean thickness; however, it is unlikely that it explains the rather striking difference in the shape of the distributions. Compared to the observational estimates NEMO-Nordic has a more bi-modal distribution which overestimates the thickness in the ranges $0.4-0.5$ and $3.0-4.0 \mathrm{~m}$, while sea ice in the thickness range $1.2-2.8 \mathrm{~m}$ is strongly underestimated. Capturing the correct ice thickness distribution is clearly challenging and several things probably affect the discrepancies. (i) The observational data set is sampled on a finer spatial scale, and thus resolves a larger thickness range before it is averaged onto the NEMO-Nordic grid. (ii) The choice of ice category bounds can impact the thickness range. However, sensitivity tests with 10 categories and two different settings of the expected mean ice thickness (rn_hicemean $=0.5$ or $1.5 \mathrm{~m}$ ) essentially yielded the same distribution as in Fig 10. (iii) The choice of maximum ridge ice thickness limit (rn_hstar) in the ridging parametrization sets the upper limit of possible ice thicknesses, and lowering it would shift the ridging peak towards the low end of the spectrum. Another possibility to improve the ice thickness distribution, which we did not explore, would be to change the transfer functions in the ridging scheme. We also note that the model used in Löptien et al. (2013) that utilizes adaptable ice category limits seems to better resolve the Baltic Sea ice thickness distribution, particularly in the 1.2-2.8 $\mathrm{m}$ range (cf. their Fig. 7a with our Fig. 10a). However, Fig. 10a also shows that there is a distinct separation between dynamically and thermodynamically grown ice in the model just below the lower limit $(1.46 \mathrm{~m})$ of the thickest ice category. This gives merit to using the four lowest ice categories as a proxy for level ice and the thickest ice category as a proxy for ridged ice. Hence we apply this concept as NEMO-Nordic does not have an explicit ice category for ridged ice.

We now compare the proxy level ice thickness, proxy ridged ice concentration and the area-integrated ice volumes in NEMO-Nordic with observational estimates from BASIS. The level ice thickness in the model is calculated as a category-weighted average of the first four ice categories; see Eq. (4). This metric mainly reflects the thermodynamical growth of the model. As seen in Fig. 11, NEMO-Nordic and BASIS agree very well on both the absolute magnitude and the spatial gradients in the level ice thickness. Both show the transition towards gradually thicker ice in the northern Bothnian Bay and eastern Gulf of Finland; there is also a gradient with thicker ice close to the coasts and thinner ice more central in the basins in both sources. The main difference is an overestimation by the model of the ice thickness in a thin band in the fast-ice zone, close to the Finnish coast, for both months. From the long-term January-April level ice 


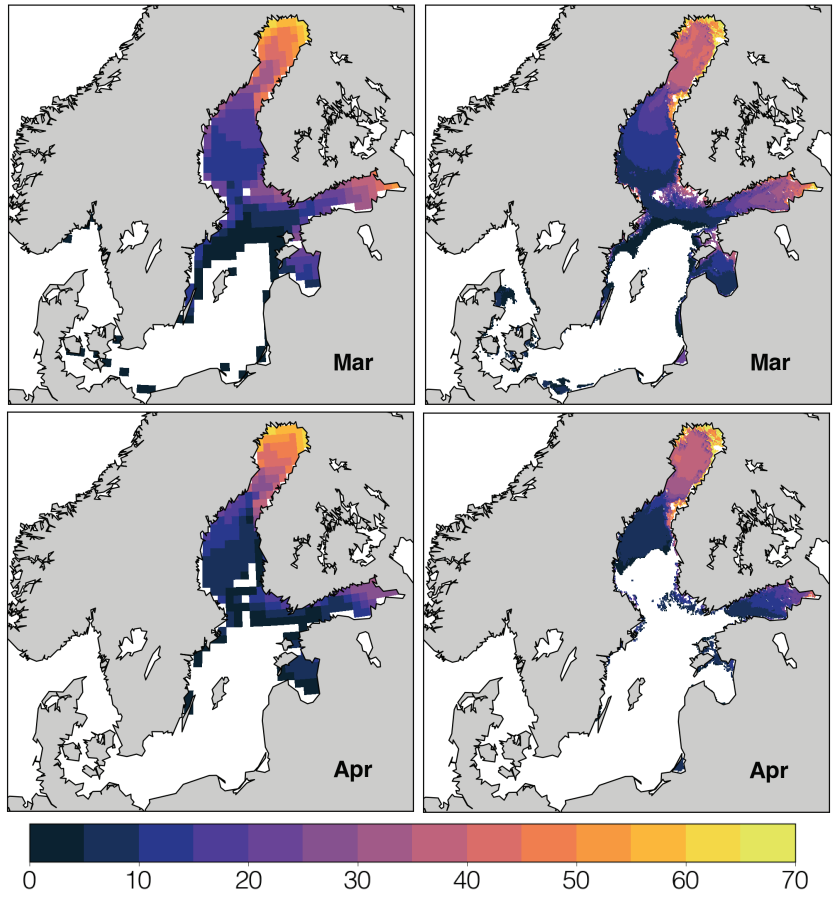

Figure 11. Climatological mean sea-ice thickness in centimeters for March and April, for the period 1961/1962-1978/1979. The left (right) column shows sea-ice thickness for BASIS (NEMO-Nordic). For NEMO-Nordic the mean sea-ice thickness represents a proxy level ice thickness and is calculated using a category-weighted average of the first four ice categories; see Eq. (4). Note that grid cells with an ice concentration lower than $15 \%$ have been masked out.

thickness means we then calculate the area-averaged level ice thickness for the total Baltic Sea, Bothnian Bay, Bothnian Sea, and Gulf of Finland, which yield for NEMO-Nordic (BASIS) 21 (18), 37 (36), 14 (11), and $22(21) \mathrm{cm}$, respectively. This shows that there is a level ice thickness bias of $17 \%$ for the total area and a $3-27 \%$ bias for the sub-areas. Given the uncertainties of the BASIS data set the agreement must be considered good.

Figure 12 compares the proxy ridge ice concentration from NEMO-Nordic with observational estimates from BASIS. Here the agreement is generally good between the model and the observational estimates: both show a high concentration in the central Bothnian Bay and lower concentrations close to the coast in the Bothnian Sea and the eastern part of the Gulf of Finland, regions where we expected to find ridges. It is also seen (see inset in Fig. 12) how the fast-ice parametrization leads to much lower deformed ice concentrations close to the coasts. However, we stress that these are two different measures of the ridging: the observations estimate the number of ridges per kilometer, while the model proxy gives the areal fraction of all ice thicker than $1.46 \mathrm{~m}$ in a model grid cell.

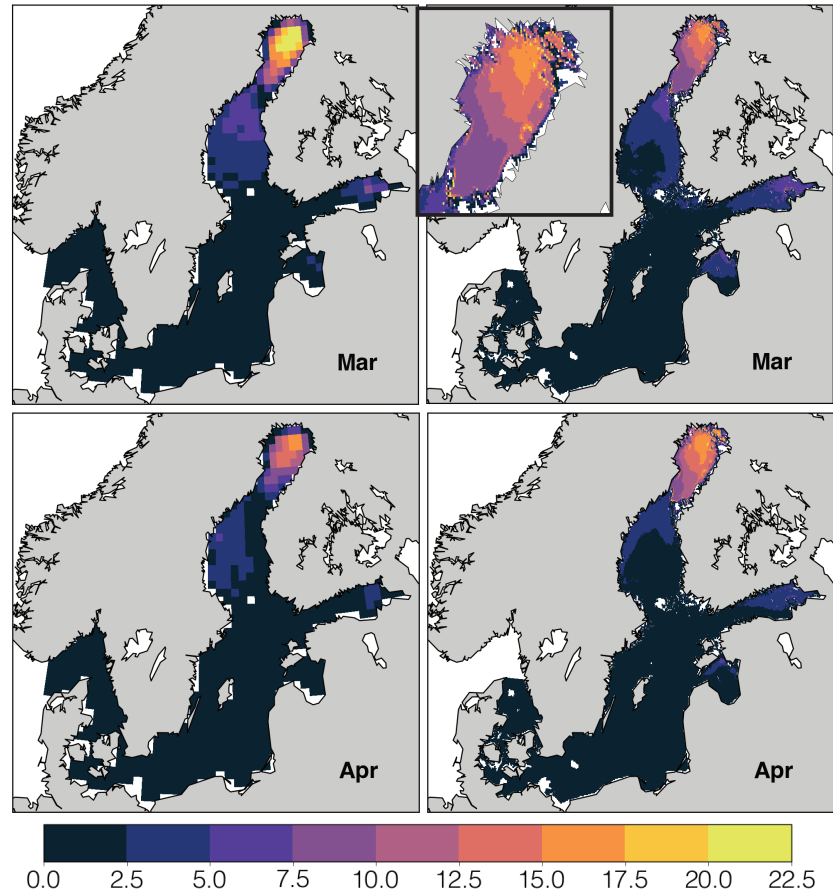

Figure 12. Climatological mean sea-ice ridge concentration in $\%$ for March and April, for the period 1961/1962-1978/1979. The left (right) column shows sea-ice ridge concentration for BASIS (NEMO-Nordic). For NEMO-Nordic the sea-ice ridge concentration is estimated from the fifth ice category. The inset shows a zoom over the Bothnian Bay for the simulated March distribution.

To further explore the composition of the different ice categories we calculate the area-integrated ice volume per ice category, integrated over the Bothnian Bay and the entire Baltic Sea, as an average of the January-April 1961-1979 period. From Fig. 13 we can see that a large portion (25$50 \%$ ) of the ice volume is found in the thickest ice category, both for the Bothnian Bay and the entire Baltic Sea, especially late in the ice season. It is also clearly seen that there is a redistribution of ice towards thicker categories as the ice season evolves, with $\sim 50 \%$ of the volume in the thickest category in April. Compared to the BASIS data set the total ice volume in NEMO-Nordic is much higher (68-123\%), particularly in the Bothnian Bay. Compared to the ice volume in only the first four categories, our proxy level ice volume, the match is better (1-68\%). During January and February the simulated level ice volume is too high, while the March (and also April for the Bothnian Bay) level ice volume almost perfectly matches the BASIS ice volume. In April the level ice volume for the entire Baltic Sea is lower than the BASIS data set, indicating an early ice retreat for this ice type, during this period, consistent with the early total ice extent retreat. Given the uncertainties of the ice thickness measurements in BASIS and that the observations of ridges are usually quite sparse, we assume that the BASIS data mainly reflect the level ice thickness and volume. As the simulated volumes imply that 

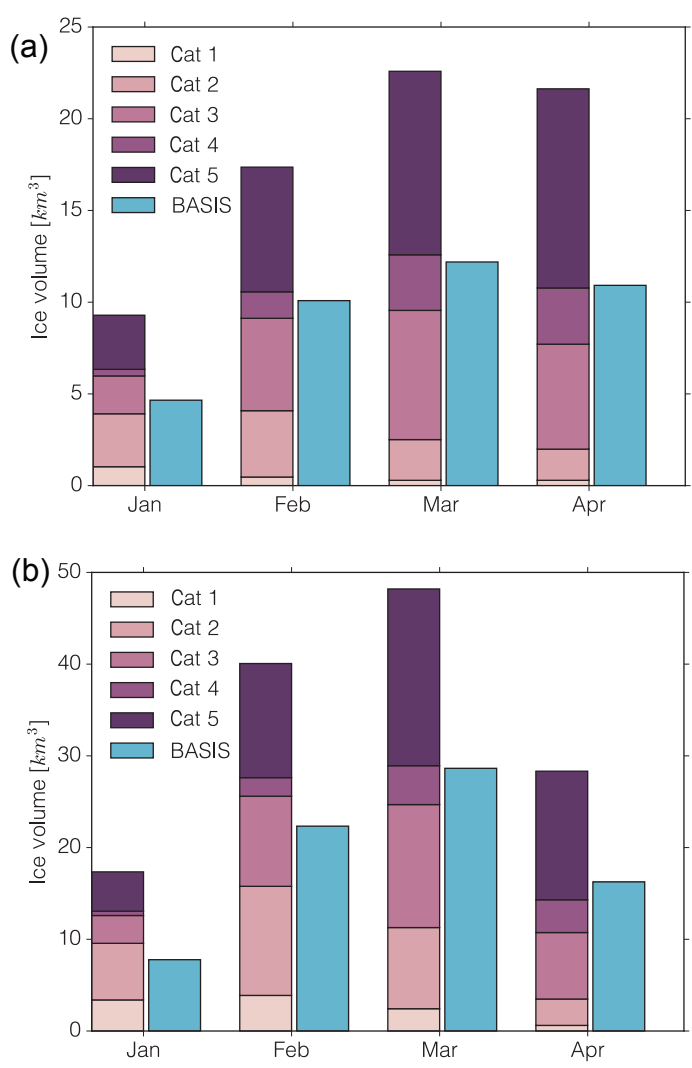

Figure 13. Climatological mean sea-ice volume for January-April, for the period 1961/1962-1978/1979, calculated for (a) the Bothnian Bay and (b) the entire Baltic Sea. Note that the NEMO-Nordic ice volumes are calculated for each ice category and the sum gives the total simulated ice volume.

the deformed ice constitutes a considerable amount of the total volume, this primarily explains the differences in total ice volumes for both the Bothnian Bay and the total domain.

Figures 11-13 show that, compared to BASIS, NEMONordic generally agrees well on the spatial patterns and areaaveraged level ice thickness, and that, if we exclude the volume in the fifth category we have an estimate of the simulated level ice volume agreeing rather well with the observed total volume. The offset in the seasonality seen in the ice extent is also seen in the level ice volume, with a tendency to overestimate the ice production in the growth phase and ice reduction in the melt phase of the season. The overly low snow thickness in the model suggests that the ice thickness and volume should be overestimated. In contrast, the warmer than observed $2 \mathrm{~m}$ air temperatures in the downscaling, as shown from some of our stations in the northern Baltic Sea and by Samuelsson et al. (2010) for nearby land areas, suggest that there should be an underestimation. We can speculate that the two effects counteract each other to some extent; however, here too we fail to fully attribute the cause since we miss observations of all heat fluxes at the ice-ocean-atmosphere interfaces.
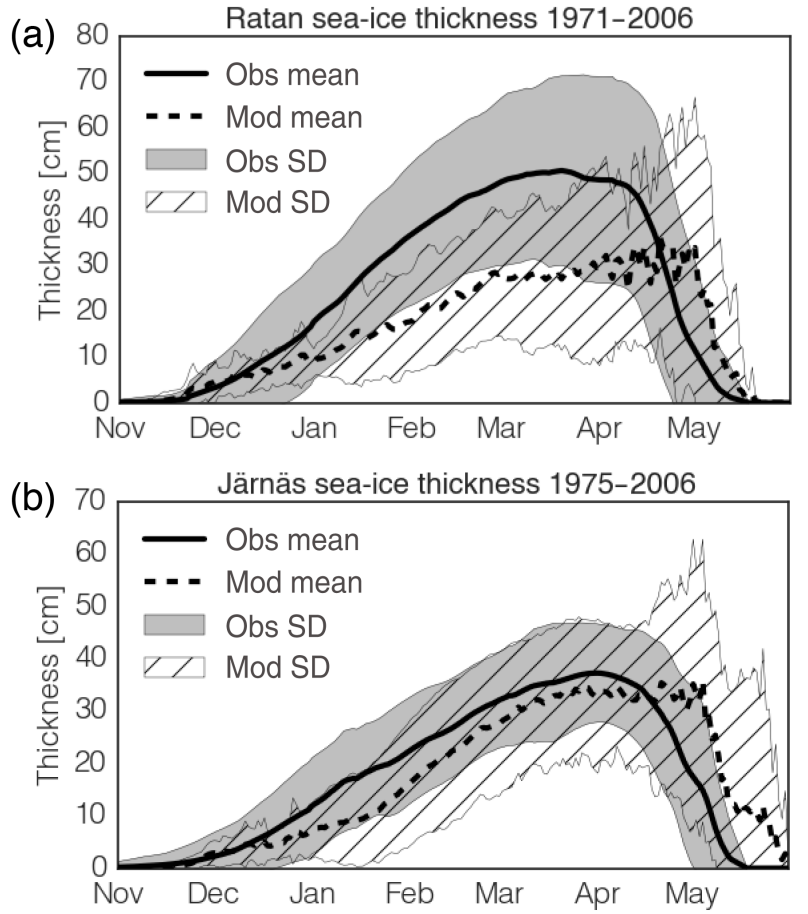

Figure 14. Seasonal simulated and observed sea-ice thickness at coastal sites (a) Ratan and (b) Järnäs. The lines show the seasonal daily means and the filled envelopes show the \pm 1 standard deviations. The seasonal cycles are calculated for the periods 1971/19722005/2006 and 1975/1976-2005/2006 for the Ratan and Järnäs sites, respectively. For the locations of the sites, see Fig. 1.

\subsection{Coastal stations in the fast-ice zone}

The sea ice in the coastal regions around the Baltic Sea usually consists of (land) fast ice which is immobile. These areas are important platforms for both human activity and marine wildlife. Here the ice pack is dominated by thermodynamical growth driven by the changes in surface air temperature. In the initial stages the wind conditions also affect the formation and extent of the fast ice. The fast-ice zone also affects the atmosphere-ocean momentum interaction as the wind stress is damped out. To evaluate the model performance we compare simulated cell-averaged ice thickness with long-term weekly ice thickness observations at two coastal stations, outside Ratan and Järnäs (see Fig. 1 for the locations).

Figure 14 shows the long-term mean and standard deviations of simulated and observed sea-ice thickness on the edge of the model's fast-ice zone at the Ratan and Järnäs sites. At the Ratan site NEMO-Nordic simulates an overly thin mean ice cover during the growth phase of the ice season, up until the observed melt starts, implying an overly slow thermodynamical growth rate. The variability for the growth phase, on the other hand, matches the observations quite well. During the observed melt phase, the simulated ice cover generally still continues to increase for 1-3 weeks more, leading to a 
shift in the mean seasonal cycle. The variability in this phase is much larger in the model, however, but the mean slope of melt matches the observations fairly well. At the Järnäs site the initial growth phase matches the observations better, with a similar growth rate and variability. The melt rate is also in line with the observation; however, there is still a shift in the mean seasonal cycle, with the melt phase occurring a few weeks later in the season.

Here we used the cell-averaged thickness in the comparison with observations. Using the proxy level ice thickness (not shown) yields a slight underestimation at the Ratan site and a larger underestimation at the more southern Järnäs site. For these coastal stations, which are just within the fast-ice mask, it is evident that there is a signal of ridged ice late in the season affecting the seasonal cycles. Just as the ice breaks up and starts melting, small concentrations of relatively thick ice are usually advected into the fast-ice zone, and thus strongly influence the variability. Our results also demonstrate that it is not straightforward to compare simulated grid-point values with point measurements, mainly due to the difference in scales. The observations represent the ice thickness for one point in space, while the cell-averaged ice thickness in a model grid cell represents the mean of the thickness distribution on the scale of $\sim 4 \mathrm{~km}$. Another contributing factor to the difference in the seasonal cycles is that the measurements rely on a stable ice cover. When the ice starts to form or break up it is much harder to go out and measure the thickness of the ice; thus, the observations at coastal stations Ratan and Järnäs underestimate the length of the ice season.

\subsection{Daily sea-ice extent and thickness for two extreme winters}

To evaluate the model performance on shorter timescales, we now briefly compare 2 single days from the hindcast with observational data from IceMap. We chose the day of the MBI for a mild winter (1995) and an extremely severe winter (1987); see, e.g., Fig. 8. In Fig. 15 we show the extent and level ice thickness for NEMO-Nordic and IceMap, where we chose the date of MBI in the IceMap data set for both sources. As seen in Fig. 15 the extent of NEMO-Nordic's ice cover agrees well with the IceMap ice cover. For the mild winter the MBI from IceMap was $64 \times 10^{3} \mathrm{~km}^{2}$ and occurred on 16 February. For NEMO-Nordic the total ice extent for the same date was $69 \times 10^{3} \mathrm{~km}^{2}$, but the seasonal maximum was somewhat larger $\left(95 \times 10^{3} \mathrm{~km}^{2}\right)$ and reached already 5 days earlier. For the extremely severe winter the MBI from IceMap was $369 \times 10^{3} \mathrm{~km}^{2}$ and reached on 5 March. Here the NEMO-Nordic total ice extent was $353 \times 10^{3} \mathrm{~km}^{2}$, while the maximum simulated extent of $377 \times 10^{3} \mathrm{~km}^{2}$ was reached 9 days later. We note that there is an offset for NEMO-Nordic both in the total size of the sea-ice extent and the time when it occurs for these two cases. The IceMap data are updated roughly two times per week, which could partly explain the offset. When the model is run in forecast mode data assim-
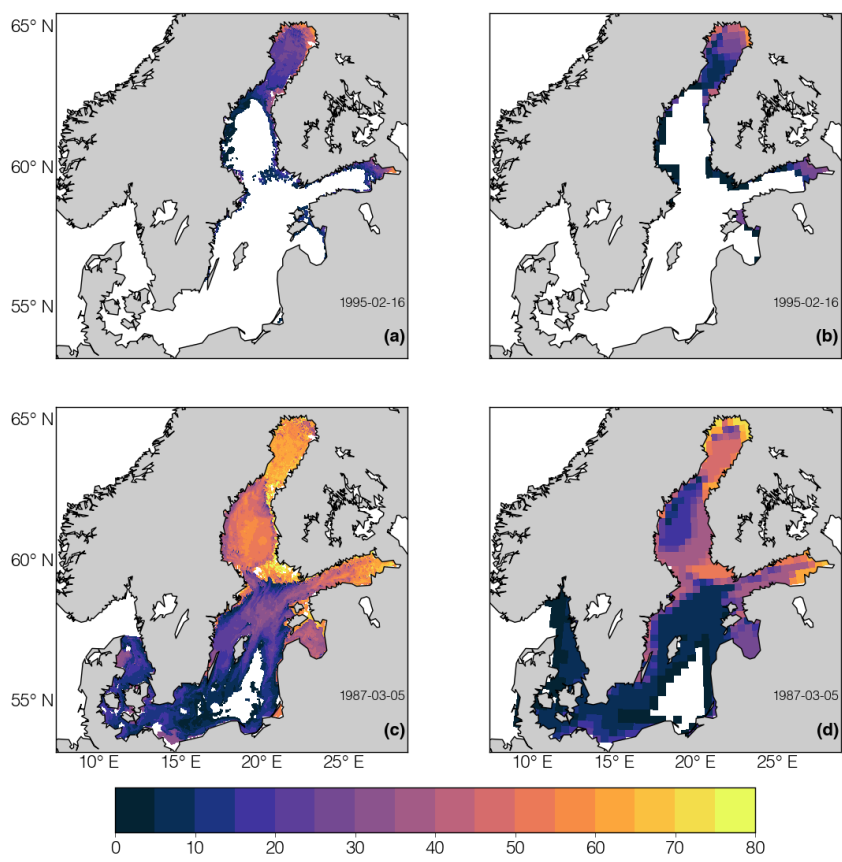

Figure 15. Daily means of level ice thickness based on IceMap data $(\mathbf{b}, \mathbf{d})$ and proxy level ice thickness from NEMO-Nordic $(\mathbf{a}, \mathbf{c})$ for the day of MBI for a mild winter - 16 February 1995 (a, b); and an extremely severe winter - 3 March 1987 (c, d). Note that grid cells with an ice concentration lower than $15 \%$ have been masked out.

ilation of SST and sea-ice concentration will also likely improve the performance of the model in terms of timing of the MBI furthermore.

For the mild winter the level ice thicknesses in NEMONordic and IceMap agree quite well with the thickest ice found in the northern parts of the Bothnian Bay, the eastern part of the Northern Quark, and the eastern part of the Gulf of Finland, while thinner ice is present in the central parts of the Bothnian Bay and along the coast of the Bothnian Sea. The area-averaged simulated ice thickness is somewhat thinner than the IceMap data. For the Bothnian Bay, Bothnian Sea, and Gulf of Finland the NEMO-Nordic (IceMap) areaaveraged thicknesses are $26(29), 10(14)$, and $21(23) \mathrm{cm}$. For the extremely severe winter, on the other hand, only the broad-scale features are similar between the two. NEMONordic generally has thicker ice compared to IceMap, except for in the northern parts of the Bothnian Bay. The areaaveraged NEMO-Nordic (IceMap) ice thicknesses for the Bothnian Bay, Bothnian Sea, and Gulf of Finland are 59 (54), 50 (31), and $53(50) \mathrm{cm}$. It is also evident in Fig. 15 that the IceMap thickness data are very patchy and only represent the large-scale features of the ice pack. 


\section{Summary and conclusions}

We have presented the ice component of a new NEMOLIM3.6-based configuration of the Baltic Sea. The model system is intended to be used for both climate studies and short-term forecasting in the Baltic Sea region. To adapt NEMO-Nordic to the Baltic Sea, a number of parametrizations were tuned to the brackish Baltic Sea conditions. Compared to, for instance, polar regions, this means that we had to tune the model to the Baltic Sea ice which is only seasonal, thinner, and has a much lower brine content. In addition, we implemented a simple fast-ice parametrization which is based on the ocean depth.

In the present study we evaluated the performance of the model by comparing results from a 45 -year long hindcast simulation, forced by data from a downscaled ERA-40 simulation, with several observational data sets. Most of our metrics are based on long-term changes in standard sea-ice parameters. However, we also briefly show how the model performs on a daily timescale by comparing daily means of the sea-ice state during the day of maximum extent for an extremely severe and mild winter.

Our results show that the NEMO-LIM3.6 modeling system is a tool well suited to being used in a regional setup of the seasonally ice-covered brackish Baltic Sea. The sea-ice concentration and extent are generally well simulated when compared to the BASIS data set over 1961-1979, although there is a bias in Kattegat, which might be related to a cold temperature bias in the air temperature forcing and the proximity to the open boundary. In some years there are also problems with too much ice in the Bothnian Bay. The downward trend of the MBI, over the 1961-2006 period, is much lower in NEMO-Nordic compared to the observational estimate. This is mainly related to the general overestimation of the ice cover in the two problem areas, which is also evident in the estimated SST biases. For the seasonal cycle of total ice extent we see an overestimation both during the growth phase and the melt phase, where the latter leads to a slightly faster ice retreat. The sea-ice thickness overall also agrees well with the observational data set. For the investigated period (1961-1979) the large-scale pattern shows good agreement between our level ice thickness estimate and the observations. The area-averaged thicknesses and area-integrated volumes of level ice are within the uncertainties of the observational estimates; also here we see an offset in the seasonal ice volumes similar to the ice cover offsets. From the mean total ice and snow thickness calculated from the ice thickness distribution, and the seasonal ice thickness at one out of two selected stations along the Swedish coast, we see that the model has a tendency to underestimate the level ice thickness relative to the observational data sets. This is somewhat contradictory to what the negative SST biases imply. For the mean total ice and snow thickness estimate based on the ice thickness distribution, we speculate that an overly thin snow cover can partly explain the difference. In our analysis we investigated biases in $2 \mathrm{~m}$ air temperature, snow thickness, and SSTs; however, as we lack a complete set of observational estimates on all the different heat flux components at the ice-ocean-atmosphere interfaces, we fail to attribute the driving causes of these anomalies.

For the demonstrated extremely severe and mild cases of day of the MBI, the total extent and spatial distributions are well in line with the observational estimate, although there is an offset in total extent and when the day occurs in the model. Here the estimated level ice thickness is generally overestimated by the model for the extremely severe case, while the mild case agrees better with the observational data. However, the observations which are weekly ice charts are very patchy and only represent the large-scale features of the ice. In addition, data assimilation of SST and sea-ice concentration will presumably improve the model skill further.

Furthermore, based on data from a few recent years, our study shows that it is challenging to accurately capture the Baltic Sea ice thickness distribution. The simulated ice thickness distribution shows a more bimodal distribution compared to the observational data set. A higher number of categories as well as shifting the resolution towards thinner or thicker ice was explored, but failed to improve the distribution. Here we suggest further fine-tuning of the ridging parameters and development of new transfer functions as a way forward to improve our model. However, we find that with the present ice category configurations the thickest ice category can be used as a proxy for ridge ice concentration and the lower four as a proxy for level ice thickness and coverage. The proxy ridged ice concentration is generally in line with the observations, and the new fast-ice parametrization yields a more realistic distribution with the ridges further off the coast.

The lack of reliable long-term and spatially representative observational data in ice-covered regions limits our study to fully explore the model performance. Here particularly more snow and ice thickness data as well as radiation data would greatly improve future sea-ice model assessments in the Baltic Sea. In addition, we caution that the observations, which are digitized hand-drawn ice charts based on ship observations and various other sources, should be interpreted with some caution, as it is difficult to accurately estimate the ice thickness and deformation using that methodology. For future evaluations more objective methods should be preferred.

Finally, we have implemented a very simple fast-ice parametrization, which is fixed based only on the ocean depth. For climate studies and forecasting purposes a more sophisticated parametrization is needed to capture long-term and seasonal changes in the fast-ice zone. Modeling of the fast-ice zone has received relatively little attention, but recent studies (Lemieux et al., 2015; Olason, 2016) have suggested new ways to parametrize the fast-ice zone, which could be feasible for a Baltic Sea ice model. 
Code and data availability. NEMO-Nordic builds on the standard NEMO code (nemo_v3_6_STABLE, revision 5628) with only minor changes, including the fast-ice parametrization and a spatial varying background viscosity/diffusivity that could be read in from the file. The standard NEMO code can be downloaded from the NEMO web site (http://www.nemo-ocean. eu/). The nemo_v3_6_STABLE version is available from the following link: http://forge.ipsl.jussieu.fr/nemo/svn/branches/2015/ nemo_v3_6_STABLE. The new code blocks that are introduced (relative to the standard NEMO code nemo_v3_6_STABLE, revision 5628) into our NEMO-Nordic code are included as supplemental material. The full NEMO-Nordic code is in a Subversion revision control system repository, available under http://54.73.141.37/ subversion/repository/source_code/trunk/NEMOGCM. However, a user account is needed to gain full access. This work used revision 339 of the NEMO-Nordic code. Access to the NEMO-Nordic code and all input data, analysis scripts, and data used to produce the figures in this study can be made available upon request to the corresponding author.

\section{The Supplement related to this article is available online at https://doi.org/10.5194/gmd-10-3105-2017- supplement.}

Competing interests. The authors declare that they have no conflict of interest.

Acknowledgements. This research is part of the BONUS STORMWINDS project with financial support from BONUS, the joint Baltic Sea research and development programme (Art 185), funded jointly by the European Union's Seventh Programme for research, technological development, and demonstration and from the Swedish research council for environment, agriculture sciences, and spatial planning (FORMAS). This work is also partly funded by the SmartSea project of the Strategic Research Council of Academy of Finland, grant no.: 292 985. We thank the Ice Service at SMHI as well as Christian Haas for providing data and the NEMO-LIM3 developers for their efforts in developing the code.

Edited by: Andrew Yool

Reviewed by: Martin Vancoppenolle, François Massonnet, and David Bailey

\section{References}

Alenius, P., Nekrasov, A., and Myrberg, K.: Variability of the baroclinic Rossby radius in the Gulf of Finland, Cont. Shelf Res., 23, 563-573, https://doi.org/10.1016/S0278-4343(03)00004-9, 2003.

Beckmann, A. and Döscher, R.: A Method for Improved Representation of Dense Water Spreading over Topography in Geopotential-Coordinate Models, J. Phys. Oceanogr., 27, 581-591, https://doi.org/10.1175/15200485(1997)027<0581:AMFIRO>2.0.CO;2, 1997.
Berg, P., Döscher, R., and Koenigk, T.: Impacts of using spectral nudging on regional climate model RCA4 simulations of the Arctic, Geosci. Model Dev., 6, 849-859, https://doi.org/10.5194/gmd-6-849-2013, 2013.

Bitz, C. M., Holland, M. M., Weaver, A. J., and Eby, M.: Simulating the ice-thickness distribution in a coupled climate model, J. Geophys. Res.-Oceans, 106, 2441-2463, https://doi.org/10.1029/1999JC000113, 2001.

Bouillon, S., Maqueda, M. A. M., Legat, V., and Fichefet, T.: An elastic-viscous-plastic sea ice model formulated on Arakawa B and C grids, Ocean Model., 27, 174-184, https://doi.org/10.1016/j.ocemod.2009.01.004, 2009.

Dietze, H., Löptien, U., and Getzlaff, K.: MOMBA 1.1 a high-resolution Baltic Sea configuration of GFDL's Modular Ocean Model, Geosci. Model Dev., 7, 1713-1731, https://doi.org/10.5194/gmd-7-1713-2014, 2014.

Eilola, K., Mårtensson, S., and Meier, H. E. M.: Modeling the impact of reduced sea ice cover in future climate on the Baltic Sea biogeochemistry, Geophys. Res. Lett., 40, 149-154, https://doi.org/10.1029/2012GL054375, 2013.

Funkquist, L. and Eckhard Kleine, E.: HIROMB An introduction to HIROMB, an operational baroclinic model for the Baltic Sea, Report Oceanography No 37, SMHI, available at: http://www. smhi.se/publikationer (last access: 16 August 2017), 2007.

Goerlandt, F., Montewka, J., Zhang, W., and Kujala, P.: An analysis of ship escort and convoy operations in ice conditions, Safety Sci., 95 195-209, https://doi.org/10.1016/j.ssci.2016.01.004, 2016.

Gröger, M., Dieterich, C., Meier, H. E. M., and Schimanke, S.: Thermal air-sea coupling in hindcast simulations for the North Sea and Baltic Sea on the NW European shelf, Tellus A, 67, 26911, https://doi.org/10.1029/2004JC002378, 2015.

Haapala, J., Markus Meier, H. E., and Rinne, J.: Numerical Investigations of Future Ice Conditions in the Baltic Sea, AMBIO, 30 237-244, https://doi.org/10.1579/0044-7447-30.4.237, 2001.

Haas, C.: Airborne EM sea-ice thickness profiling over brackish Baltic sea water, in: 17th International Symposium on Ice, Saint Petersburg, Russia, 1-17, 2004.

HELCOM: Recommendation 25/7 on Safety of winter navigation in the Baltic Sea Area, Baltic Marine Environment Protection Commission (Helsinki Commission), available at: http://www. helcom.fi/ (last access: 16 August 2017), 2004.

HELCOM: Ensuring safe shipping in the Baltic, Baltic Marine Environment Protection Commission (Helsinki Commission), available at: http://www.helcom.fi/ (last access: 16 August 2017), 2009.

Hordoir, R. and Meier, H. E. M.: Effect of climate change on the thermal stratification of the baltic sea: a sensitivity experiment, Clim. Dynam., 38, 1703-1713, https://doi.org/10.1007/s00382011-1036-y, 2011.

Hordoir, R., Dieterich, C., Basu, C., Dietze, H., and Meier, H. E. M.: Freshwater outflow of the Baltic Sea and transport in the Norwegian current: A statistical correlation analysis based on a numerical experiment, Cont. Shelf Res., 64, 1-9, https://doi.org/10.1016/j.csr.2013.05.006, 2013.

Hordoir, R., Axell, L., Löptien, U., Dietze, H., and Kuznetsov, I.: Influence of sea level rise on the dynamics of salt inflows in the Baltic Sea, J. Geophys. Res., 120, 6653-6668, https://doi.org/10.1002/2014JC010642, 2015. 
Hordoir, R., et al.: A NEMO based ocean model for Baltic \& North Seas, research and operational applications, in preparation, 2017.

Hunke, E. and Holland, M. M.: Global atmospheric forcing data for Arctic ice-ocean modeling, J. Geophys. Res., 112, C04S14, https://doi.org/10.1029/2006JC003640, 2007.

Jones, C. G., Willén, U., Ullerstig, A., and Hansson, U.: The Rossby Centre Regional Atmospheric Climate Model Part I: Model Climatology and Performance for the Present Climate over Europe, AMBIO, 33, 199-210, https://doi.org/10.1579/0044-744733.4.199, 2004.

Lemieux, J.-F., Tremblay, L. B., Dupont, F., Plante, M., Smith, G. C., and Dumont, D.: A basal stress parameterization for modeling landfast ice, J. Geophys. Res., 120, 3157-3173, https://doi.org/10.1002/2014JC010678, 2015.

Leppäranta, M. and Hakala, R.: The structure and strength of firstyear ice ridges in the Baltic Sea, Cold Reg. Sci. Technol., 20, 295-311, https://doi.org/10.1016/0165-232X(92)90036-T, 1992.

Leppäranta, M. and Myrberg, K.: Physical oceanography of the Baltic Sea, Springer Science and Business Media, 2009.

Leppäranta, M., Sun, Y., and Haapala, J.: Comparisons of Sea-Ice Velocity Fields from ERS-1 SAR and a dynamic model, J. Glaciol., 44, 248-262, https://doi.org/10.1017/S0022143000002598, 1998.

Loewe, P.: Surface temperatures of the North Sea in 1996, Ocean Dynam., 48, 175-184, 1996.

Löptien, U. and Axell, L.: Ice and AIS: ship speed data and sea ice forecasts in the Baltic Sea, The Cryosphere, 8, 2409-2418, https://doi.org/10.5194/tc-8-2409-2014, 2014.

Löptien, U. and Dietze, H.: Sea ice in the Baltic Sea - revisiting BASIS ice, a historical data set covering the period 1960/1961-1978/1979, Earth Syst. Sci. Data, 6, 367-374, https://doi.org/10.5194/essd-6-367-2014, 2014 (data available at: https://doi.org/10.1594/PANGAEA.832353), last access: $16 \mathrm{Au}-$ gust 2017.

Löptien, U. and Meier, H. E. M.: The influence of increasing water turbidity on the sea surface temperature in the Baltic Sea: A model sensitivity study, J. Marine Syst., 88, 323-331, https://doi.org/10.1016/j.jmarsys.2011.06.001, 2011.

Löptien, U., Mårtensson, S., Meier, H. E. M., and Höglund, A.: Long-term characteristics of simulated ice deformation in the Baltic Sea (1962-2007), J. Geophys. Res., 118, 801-815, https://doi.org/10.1002/jgrc.20089, 2013.

Madec, G.: NEMO ocean engine, Note du Pole de modélisation No 27, Institut Pierre-Simon Laplace (IPSL), available at: www. nemo-ocean.eu (last access: 16 August 2017), 2016.

Meier, H. E. M.: Baltic Sea climate in the late twenty-first century: a dynamical downscaling approach using two global models and two emission scenarios, Clim. Dynam., 27, 39-68, https://doi.org/10.1007/s00382-006-0124-x, 2006.

Meier, H. E. M., Döscher, R., and Faxen, T.: A multiprocessor coupled ice-ocean model for the Baltic Sea: Application to salt inflow, J. Geophys. Res., 108, 3273, https://doi.org/10.1029/2000JC000521, 2003.

Meier, H. E. M., Döscher, R., and Halkka, A.: Simulated distributions of Baltic Sea-ice in warming climate and consequences for the winter habitat of the Baltic ringed seal, AMBIO, 33, 249256, 2004.

Meier, H. E. M., Höglund, A., Döscher, R., Andersson, H., Löptien, U., and Kjellström, E.: Quality assessment of atmospheric surface fields over the Baltic Sea from an ensemble of regional climate model simulations with respect to ocean dynamics, Oceanologia, 53, 193-227, https://doi.org/10.5697/oc.53-1TI.193, 2011.

Meier, H. E. M., Hordoir, R., Andersson, H. C., Dieterich, C., Eilola, K., Gustafsson, B. G., Höglund, A., and Schimanke, S.: Modeling the combined impact of changing climate and changing nutrient loads on the Baltic Sea environment in an ensemble of transient simulations for 1961-2099, Clim. Dynam., 39, 2421-2441, https://doi.org/10.1007/s00382-012-1339-7, 2012.

Montewka, J., Goerlandt, F., Kujala, P., and Lensu, M.: Towards probabilistic models for the prediction of a ship performance in dynamic ice, Cold Reg. Sci. Technol., 112, 14-28, https://doi.org/10.1016/j.coldregions.2014.12.009, 2015.

Olason, E.: A dynamical model of Kara Sea landfast ice, J. Geophys. Res., 121, 3141-3158, https://doi.org/10.1002/2016JC011638, 2016.

Osinski, R., Rak, D., Walczowski, W., and Piechura, J.: Baroclinic Rossby radius of deformation in the southern Baltic Sea, Oceanologia, 52, 417-429, 2010.

Parmerter, R. R.: A model of simple rafting in sea ice, J. Geophys. Res., 80, 1948-1952, https://doi.org/10.1029/JC080i015p01948, 1975.

Rousset, C., Vancoppenolle, M., Madec, G., Fichefet, T., Flavoni, S., Barthélemy, A., Benshila, R., Chanut, J., Levy, C., Masson, S., and Vivier, F.: The Louvain-La-Neuve sea ice model LIM3.6: global and regional capabilities, Geosci. Model Dev., 8, 29913005, https://doi.org/10.5194/gmd-8-2991-2015, 2015.

Samuelsson, P., Jones, C. G., Willén, U., Ullerstig, A., Gollvik, S., Hansson, U., Jansson, C., Kjellström, E., Nikulin, G., and Wyser, K.: The Rossby Centre Regional Climate model RCA3: model description and performance, Tellus A, 63, 4-23, https://doi.org/10.1111/j.1600-0870.2010.00478.x, 2010.

Seinä, A. and Paluso, E.: The classification of the maximum annual extent of ice cover in the Baltic Sea 1720-1995, Report series of the Finnish Institute of Marine Research No 20, Finnish Institute of Marine Research, 1996.

Thorndike, A. S., Rothrock, D. A., Maykut, G. A., and Colony, R.: The thickness distribution of sea ice, J. Geophys. Res., 80, 45014513, https://doi.org/10.1029/JC080i033p04501, 1975.

Umlauf, L. and Burchard, H.: Second-order turbulence closure models for geophysical boundary layers. A review of recent work, Cont. Shelf Res., 25, 795-827, https://doi.org/10.1016/j.csr.2004.08.004, 2005.

Uppala, S. M., Kållberg, P. W., Simmons, A. J., Andrae, U., Bechtold, V. D. C., Fiorino, M., Gibson, J. K., Haseler, J., Hernandez, A., Kelly, G. A., Li, X., Onogi, K., Saarinen, S., Sokka, N., Allan, R. P., Andersson, E., Arpe, K., Balmaseda, M. A., Beljaars, A. C. M., Berg, L. V. D., Bidlot, J., Bormann, N., Caires, S., Chevallier, F., Dethof, A., Dragosavac, M., Fisher, M., Fuentes, M., Hagemann, S., Hólm, E., Hoskins, B. J., Isaksen, L., Janssen, P. A. E. M., Jenne, R., Mcnally, A. P., Mahfouf, J. F., Morcrette, J. J., Rayner, N. A., Saunders, R. W., Simon, P., Sterl, A., Trenberth, K. E., Untch, A., Vasiljevic, D., Viterbo, P., and Woollen, J.: The ERA-40 re-analysis, Q. J. Roy. Meteor. Soc., 131, 29613012, https://doi.org/10.1256/qj.04.176, 2006.

Valdez Banda, O., Goerlandt, F., Montewka, J., and Kujala, P.: A risk analysis of winter navigation in Finnish sea areas, Accident Anal. Prev., 79, 100-116, 2015. 
Vancoppenolle, M., Fichefet, T., Goosse, H., Bouillon, S. Madec, G., and Maqueda, M. A. M.: Simulating the mass balance and salinity of Arctic and Antarctic sea ice. 1. Model description and validation, Ocean Model., 27, 33-53, https://doi.org/10.1016/j.ocemod.2008.10.005, 2009.
Vihma, T. and Haapala, J.: Geophysics of sea ice in the Baltic Sea: A review, Prog. Oceanogr., 80, 129-148, https://doi.org/10.1016/j.pocean.2009.02.002, 2009.

Weeks, W. F.: On sea ice, Universiy of Alaska Press, Fairbanks, 1st Edn., 664 pp., 2010. 